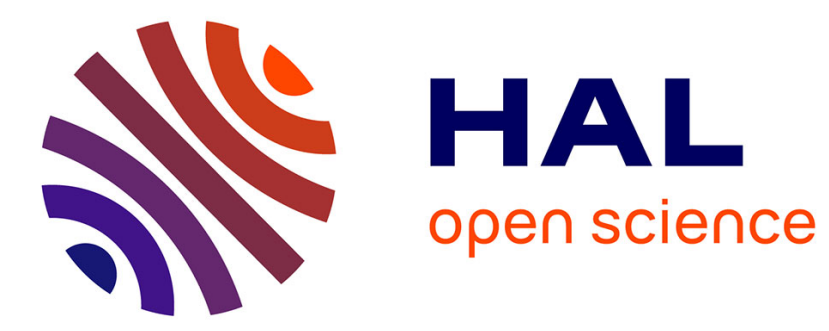

\title{
In vitro toxicity of carbon nanotubes, nano-graphite and carbon black, similar impacts of acid functionalization
} Agathe Figarol, Jérémie Pourchez, Delphine Boudard, Valérie Forest, Céline Akono, Jean-Marc Tulliani, Jean-Pierre Lecompte, Michèle Cottier, Didier Bernache-Assolant, Philippe Grosseau

\section{To cite this version:}

Agathe Figarol, Jérémie Pourchez, Delphine Boudard, Valérie Forest, Céline Akono, et al.. In vitro toxicity of carbon nanotubes, nano-graphite and carbon black, similar impacts of acid functionalization. Toxicology in Vitro, 2015, 30 (1 Part B), pp.476-485. 10.1016/j.tiv.2015.09.014 . emse-01212432

HAL Id: emse-01212432

https://hal-emse.ccsd.cnrs.fr/emse-01212432

Submitted on 16 Nov 2015

HAL is a multi-disciplinary open access archive for the deposit and dissemination of scientific research documents, whether they are published or not. The documents may come from teaching and research institutions in France or abroad, or from public or private research centers.
L'archive ouverte pluridisciplinaire HAL, est destinée au dépôt et à la diffusion de documents scientifiques de niveau recherche, publiés ou non, émanant des établissements d'enseignement et de recherche français ou étrangers, des laboratoires publics ou privés. 
In vitro toxicity of carbon nanotubes, nano-graphite and carbon black, similar impacts of acid functionalization

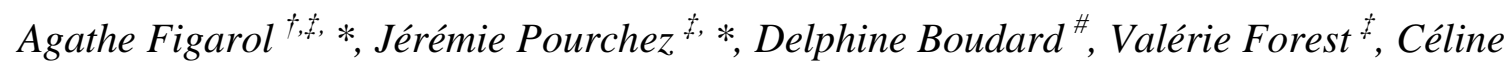
Akono $^{\dagger}$, Jean-Marc Tulliani ${ }^{\beta}$, Jean-Pierre Lecompte ${ }^{\star}$, Michèle Cottier ${ }^{\#}$, Didier BernacheAssollant ${ }^{*}$, Philippe Grosseau ${ }^{*}$

${ }^{\dagger}$ Ecole Nationale Supérieure des Mines, SPIN-EMSE, CNRS: UMR 5307, LGF, F-42023

Saint-Etienne (France), ${ }^{\ddagger}$ Ecole Nationale Supérieure des Mines, CIS-EMSE, EA 4624, SFR

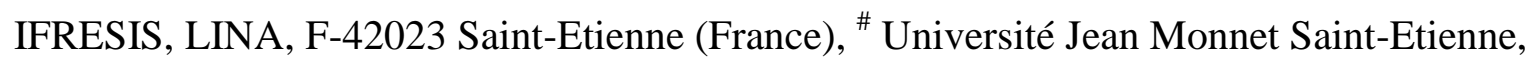
EA 4624, SFR IFRESIS, LINA, F-42023 Saint-Etienne; CHU de Saint-Etienne F-42055, Saint-Etienne (France), ${ }^{\beta}$ Politecnico di Torino, Department of Applied Science and Technology, 10129 Torino (Italy), ${ }^{\not}$ SPCTS Centre Européen de la Céramique CNRS: UMR 7315, F-87068 Limoges, (France).

* Correspondence to: figarol@emse.fr or pourchez@emse.fr +33(0)4 77420180

\section{ABSTRACT}

Carbon nanotubes (CNT) and nano-graphite (NG) are graphene-based nanomaterials which share exceptional physicochemical properties, but whose health impacts are unfortunately still not well understood. On the other hand, carbon black (CB) is a conventional and widely studied material. The comparison of these three carbon-based nanomaterials is thus of great interest to improve our understanding of their toxicity. An acid functionalization was carried out on CNT, NG and CB so that, after a thorough characterization, their impacts on RAW 264.7 macrophages could be compared for a similar surface chemistry (15 to $120 \mu \mathrm{g} . \mathrm{mL}^{-1}$ nanomaterials, 90-min to 24-h contact). Functionalized nanomaterials triggered a weak cytotoxicity similar to the pristine nanomaterials. Acid functionalization increased the pro- 
inflammatory response except for $\mathrm{CB}$ which did not trigger any TNF- $\alpha$ production before or after functionalization, and seemed to strongly decrease the oxidative stress. The toxicological impact of acid functionalization appeared thus to follow a similar trend whatever the carbonbased nanomaterial. At equivalent dose expressed in surface and equivalent surface chemistry, the toxicological responses from murine macrophages to NG were higher than for CNT and CB. It seemed to correspond to the hypothesis of a platelet and fiber paradigm.

\section{GRAPHICAL ABSTRACT}

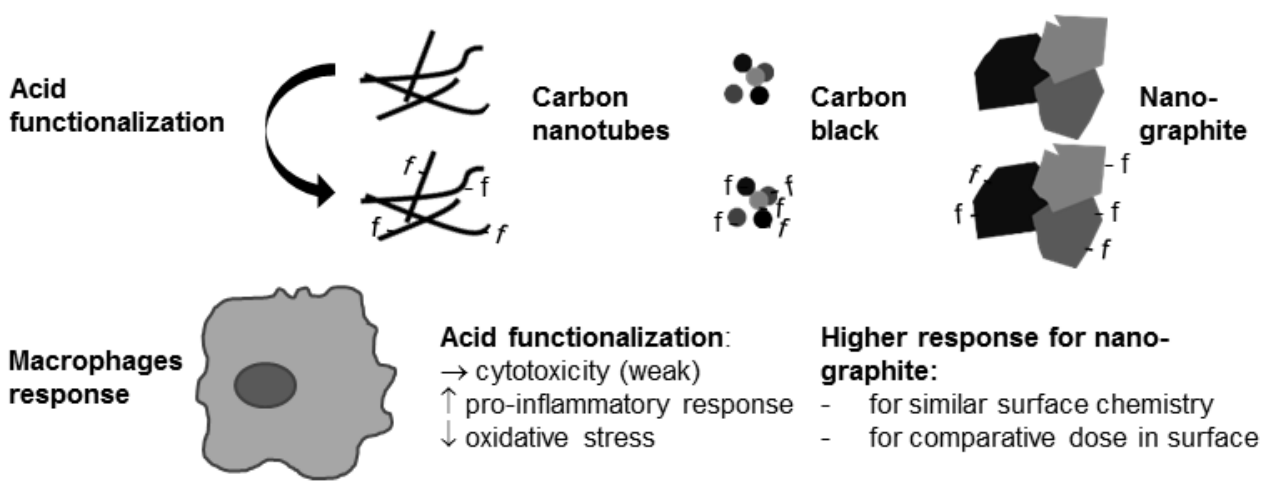

KEYWORDS: carbon black; carbon nanotubes; graphene; nano-graphite; acid functionalization; biological toxicity

\section{INTRODUCTION}

Carbon-based nanomaterials share a unique place in nanotechnologies due to their exceptional electrical, thermal, chemical and mechanical properties. In the last decades, new allotropic forms of carbon were discovered and completed this group. In the present study, a focus will be made on carbon-based nanomaterials with three nanometric dimensions: carbon black (CB), two nanometric dimensions: carbon nanotubes (CNT), and one nanometric dimension graphene or nano-graphite (NG). 
$\mathrm{CB}$ is a traditional carbon material widely used as a pigment or reinforcing phase in tires. It has been considered as nanomaterial only since a few years. CB typically falls within the ISO definition of a nanomaterial (ISO/TS 27687:2008, 2008) with primary particle diameters between 10 and $100 \mathrm{~nm}$. The health effects of CB have been extensively studied. The International Agency for Research on Cancer (IARC) has classified CB as possible carcinogenic to humans (Group 2B) (IARC, 2010). The IARC reviewed notably an in vivo study showing that lung cancer in rats caused by an exposure to CB started after signs of inflammation, cell injury and oxidative stress with the production of reactive oxygen species (ROS).

CNT and graphene are two carbon-based nanomaterials that have demonstrated exciting physicochemical properties since their late discovery, promising thus numerous industrial applications. Multi-walled and single-walled carbon nanotubes (MWCNT and SWCNT respectively) have been studied since the 1990s (Iijima, 1991; Iijima and Ichihashi, 1993). Graphene was first not thought to be a stable material until Novoselov et al. in 2004 managed to prepare and study a single graphene layer (Novoselov et al., 2004). MWCNT and SWCNT are now produced at an industrial scale, while it is still uneasy to produce graphene at large scale. Most industrials sell nano-graphite (NG), also called graphite nanoplatelets, which is composed of a few layers of graphene and has close physicochemical properties. Their mechanical resistance, electrical conductance and thermal stability are, however, decreasing with the number of graphene layers, i.e. the thickness of the NG.

Compared to $\mathrm{CNT}$ or NG, $\mathrm{CB}$ is either used in toxicity studies as a negative control (Bottini et al., 2006; Lam et al., 2004; Schinwald et al., 2011) or a positive control (Di Giorgio et al., 2011; Pulskamp et al., 2007). Due to the late discovery of CNT and NG and the lack of comparable studies, the toxicity data are still incomplete for these nanomaterials. It has been shown that CNT and NG have the potential to trigger inflammation, cytotoxicity and 
oxidative stress (Chen et al., 2011; Schinwald et al., 2011; Zhang et al., 2012). However, there is no unique toxicity for one type of nanomaterial. There are multiple toxicity profiles depending on the nanomaterial physicochemical properties. It is therefore crucial to fully characterize the nanomaterials before any toxicity study.

Few studies have yet compared the biological effects of CNT and NG. Zhang et al. (Zhang et al., 2010) studied the in vitro impacts of NG and SWCNT. The cytotoxicity and oxidative stress in PC12 cell line (derived from a neuroendocrine tumor) were found globally equivalent. However, the cytotoxicity results were dependent of the test used: MTT or LDH. Using a MTT test with a different cell line (human hepatoma HepG2 cells) Yuan et al. (Yuan et al., 2011) observed a higher cytotoxicity for SWCNT than for NG. Nevertheless, MTT is controversial because of biases induced by the CNT (Belyanskaya et al., 2007; Wörle-Knirsch et al., 2006). In their in vivo study, Ma-Hock et al. (Ma-Hock et al., 2013) assessed the biological impacts on Wistar rats of a head-nose inhalation of graphene, NG, MWCNT, and CB. Only local inflammation with no further toxicity was detected, with this order of gravity: MWCNT > graphene $>\mathrm{NG}>\mathrm{CB}$ with $\mathrm{CB}$ not inducing any inflammation. Overall, the results remained inconsistent between the toxicological studies. One explanation for these inconsistencies could be the difference in surface chemistry. Indeed, NG and CNT were produced by different methods along the studies and exhibited different level of metallic impurities and oxygen-containing groups.

One way to equalize the surface chemistry of carbon-based nanomaterials is to functionalize their surface by an acid treatment (Figarol et al., 2014). Acid functionalization of CNT is relatively easy to carry out and of great interest for industrials. The CNT hydrophobicity is indeed decreased, so they become more dispersible in aqueous solvents. Moreover, this process purifies the CNT from their metallic impurities, residues of the catalysts used for their production and entrapped into the CNT structure that are dissolved after a strong acid 
treatment. NG are often produced by the Hummers modified method (Hummers and Offeman, 1958) using strong acids to exfoliate graphite, resulting in thin flakes of oxidized NG. The biological impact of the oxygen-containing groups on CNT or NG is still not fully understood. In a previous study (Figarol et al., 2014), we demonstrated that surface acid groups increased the pro-inflammatory response and, to a lesser extent, the cytotoxicity of murine macrophages (RAW 264.7) exposed to functionalized CNT. This trend seemed to be dependent of a threshold in surface acid groups, related to the physicochemical properties of pristine CNT. Other studies showed contradictory results but did not isolate the effects of the CNT purification. In this way, even when selecting the same cell line (i.e. murine macrophages RAW 264.7), the results can be inconsistent. Dong et al. and Wang et al. (Dong et al., 2012; Wang et al., 2012) found similarly that CNT acid functionalization enhanced the cytotoxicity and the pro-inflammatory response, while Zhang et al. (Zhang et al., 2012) observed a decreased cytotoxicity and only a slight increase in the pro-inflammatory response. On the contrary, Fraczek-Szczypta et al. (Fraczek-Szczypta et al., 2012) detected no change in cytotoxicity but a decrease in cell proliferation due to the CNT acid functionalization. For NG or graphene, the results are more consistent. Oxidized graphene from Hummers method and acid functionalized graphene seemed to decrease the cytotoxicity and oxidative stress compared to exfoliated or pristine NG (Duch et al., 2011; Sasidharan et al., 2012, 2011). The pro-inflammatory response was on the other hand either found to be increased by acid functionalization (Duch et al., 2011) or decreased (Sasidharan et al., 2012). Overall, the understanding of the biological impact of an acid functionalization is still incomplete. To our knowledge, only Zhang et al. (Zhang et al., 2012) compared the in vitro response of CNT and NG with surface acid groups. Differences in cellular uptake were observed between functionalized MWCNT, oxidized NG and nano-diamonds. However, the cytotoxicity of acid 
functionalized MWCNT, and oxidized NG were not significantly different. The proinflammatory response and oxidative stress were unfortunately not assessed.

In the present study, a first objective was to determine if acid functionalization impacts the in vitro cellular response of murine macrophages with a similar pattern for different shapes of carbon-based nanomaterials (i.e. nanotubes, nanoplatelets or nanospheres). Secondly, the biological impacts of acid functionalized MWCNT, CB, and NG showing a similar surface chemistry were compared.

\section{MATERIAL AND METHODS}

\section{Powders}

The multi-walled carbon nanotubes $\left(\mathrm{NC} 7000^{\mathrm{TM}}\right.$, Nanocyl, called CNT) were synthetized by CVD (chemical vapor deposition) and have a diameter of $9.5 \mathrm{~nm}$ and a length of $1.5 \mu \mathrm{m}$ according to the manufacturers. The nano-graphite (NG) was purchased from Graphene Supermarket. The flakes have a $12 \mathrm{~nm}$ average thickness and a $4.5 \mu \mathrm{m}$ average particle size according to the manufacturers. Carbon black (CB) was purchased from Evonik Degussa (Printex $\left.{ }^{\circledR} 85\right)$.

\section{Acid functionalization}

The acid treatment consisted in an oxidation by refluxing the carbon nanopowders in a solution of nitric and sulfuric acids $(3: 1 \mathrm{v} / \mathrm{v})$. Functionalized nanomaterials were filtered $(0.025 \mu \mathrm{m}$ MF-Millipore Membrane) and rinsed until the $\mathrm{pH}$ reached 5. They were dried in an oven at $100^{\circ} \mathrm{C}$ for $18 \mathrm{~h}$. Concentrations in nanopowders, acid solutions and duration of the oxidation were optimized for each nanomaterial to obtain a comparable level of surface acid groups (see supplementary material Table A1). Functionalized carbon-based nanomaterials were called CNTf, CBf and NGf in contrast to non-functionalized nanomaterials i.e. pristine 
nanomaterials (CNT CB and NG). The term pristine will be used even after the dispersion of nanomaterials into the biological medium even though their secondary properties are affected.

\section{Physicochemical characterization}

Morphologies of the carbon-based nanomaterials were observed using field-emission scanning electron microscopy (FEG-SEM, JEOL JSM 6500F, Akishima, Tokyo, Japan) at a 2 $\mathrm{kV}$. A few milligrams of nanopowder were put on a carbon-coated holey film. Samples were coated with a $3 \mathrm{~nm}$ gold layer before FEG-SEM observations. CNT, CNTf, CB and CBf average diameters were measured using FEG-SEM images. ImageJ software was used to measure 100 diameters per picture (repeated three times). Average diameters were expressed as the mean of 300 measurements. Atomic force microscopy (AFM, JPK Nanowizard®) was used to confirm the dimensions of the NG and NGf. Samples were prepared by the sonication of a $10 \mathrm{mg} \cdot \mathrm{mL}^{-1} \mathrm{NG}$ or NGf suspension in distilled water (5 min, 30\%, $3 \mathrm{~mm}$ probe, Branson Sonifier). One drop was deposited on a $1 \mathrm{~cm}^{2}$ silicon wafer, spread by centrifugation $(226 \mathrm{~g}, 2$ min, Megafuge 16R, Thermo Scientific), and dried $10 \mathrm{~min}$ at $100^{\circ} \mathrm{C}$. Specific surface areas $\left(\mathrm{SSA}, \mathrm{m}^{2} \cdot \mathrm{g}^{-1}\right.$ ) were determined by the Brunauer-Emmet-Teller (BET) method, using $\mathrm{N}_{2}$ adsorption at $77 \mathrm{~K}$ after out-gassing at $110^{\circ} \mathrm{C}$ (Micromeritics ASAP 2000).

After acid functionalization, increase in structural defects were analyzed by Raman spectroscopy (XploRA, Horiba Scientific) with a laser at $532 \mathrm{~nm}$, a x50 objective, a $2400 \mathrm{~T}$ network, 20 acquisitions of $20 \mathrm{~s}$ giving a spectra between 1000 and $2000 \mathrm{~cm}^{-1}$. Around 1340 $\mathrm{cm}^{-1}$, the D-band (D for disorder) is linked to the $\mathrm{sp}^{3}$ hybridized carbon. Its intensity increases with ill-organized graphite structure (Belin and Epron, 2005). Around $1570 \mathrm{~cm}^{-1}$, the G-band ( $\mathrm{G}$ for graphite) corresponds to a splitting of the E2g stretching mode of graphite. Its intensity is independent from the structural defects. The ratio of both intensities Id/Ig informs on the level of structural lattice defects. Inductively coupled plasma atomic emission spectroscopy 
(ICP-AES) was used to determine trace metals after mineralization by nitro-hydrochloric acid. It indicated the level of catalytic impurities of the nanomaterials.

The levels of surface acid groups were measured by X-ray photoelectron spectroscopy (XPS) and thermal desorption spectroscopy (TDS). The atomic ratio in percentage of $\mathrm{O} / \mathrm{C}$ was assessed by XPS (with 20\% incertitude Thermo VG Thetaprobe, monochromatized Al Ka source, $400 \mu \mathrm{m}$ width analyzed, $1.3 \times 10-7 \mathrm{~Pa}$ of residual pressure). A $1 \mathrm{~cm}^{2}$ silicon wafer was covered by a $5 \mathrm{~nm}$ gold layer to avoid $\mathrm{O}$ contribution from the substrate. One drop of a sonicated $30 \mu \mathrm{g} \cdot \mathrm{mL}^{-1}$ suspension of nanomaterials in ethanol (5 min, 30\%, $3 \mathrm{~mm}$ probe) was deposited on the substrate. The spectra were corrected for Shirley-type backgrounds. Automatic search of the peak positions was conducted from the fixed C1s peak at $284.5 \mathrm{eV}$. Atomic percentages were calculated from the peak areas and given sensitivity factors. For TDS, $10 \mathrm{mg}$ of carbon nanopowder were heated under vacuum at a heating rate of $20^{\circ} \mathrm{C} \cdot \mathrm{min}^{-1}$ until $850^{\circ} \mathrm{C}$. Two turbomolecular pumps ensured a vacuum of less than $10^{-2} \mathrm{~Pa}$ from air atmosphere. A mass spectrophotometer (Balzers QMG 112 quadrupole) collected and analyzed the volatilized elements. Differences in zeta potentials were measured using a Zetasizer Nano ZS (Malvern Instruments). $30 \mu \mathrm{g} \cdot \mathrm{mL}^{-1}$ suspensions of nanomaterials in distilled water were prepared by sonication ( $5 \mathrm{~min}, 30 \%, 3 \mathrm{~mm}$ probe) for the measurement of zeta potential and isoelectric point $(\mathrm{pI})$.

\section{In vitro toxicity assays}

\subsection{Cell culture}

RAW 264.7 macrophages were provided by ATCC Cell Biology Collection (Promochem LGC). This cell line derived from mice peritoneal macrophages modified by the Albeson Murine Leukemia Virus. This cell line is widely studied, robust and allows repeatable results. Cells were cultured in Dulbecco's Modified Eagle's Medium (DMEM, Invitrogen) 
supplemented with 10\% fetal calf serum (Invitrogen), 1\% penicillin-streptomycin (10 000 U.mL $L^{-1}$ and $10 \mathrm{mg} \cdot \mathrm{mL}^{-1}$ respectively, Sigma-Aldrich). They were maintained at $37^{\circ} \mathrm{C}$ under a $5 \% \mathrm{CO}_{2}$ humidified atmosphere.

\subsection{Suspensions of carbon-based nanomaterials}

A first suspension at $160 \mu \mathrm{g} \cdot \mathrm{mL}^{-1}$ carbon-based nanomaterials in supplemented DMEM was prepared in a confined laboratory. Dispersion was carried out by sonication ( $5 \mathrm{~min}, 30 \%, 3$ mm probe). Serial dilutions were conducted to obtain concentrations of 160, 80, 40, 20 $\mu \mathrm{g} . \mathrm{mL}^{-1}$ of nanomaterials in supplemented DMEM. For the toxicity assays, $1 / 4$ cells suspensions, $3 / 4$ nanomaterials in volume were poured into the wells of 96-well plate. The final concentrations of exposure were thus $120,60,30$, and $15 \mu \mathrm{g} \cdot \mathrm{mL}^{-1}$. There are within the range of commonly used concentrations (Dong et al., 2012; Fraczek-Szczypta et al., 2012; Wang et al., 2012; Zhang et al., 2012), and have been considered as pertinent by Vietti et al. considering the approximations inherent to an in vitro study (Vietti et al., 2013). The suspension stability was confirmed over 4 days by dynamic light scattering (Zetasizer Nano ZS, see supplementary data Figure A1).

\subsection{Cytotoxicity}

The dosage of extracellular Lactate dehydrogenase (LDH) leaking from cells with damaged membrane was used to evaluate the cytotoxicity. Cells were seeded in a 96-well plate at 100000 cells/well and exposed for $24 \mathrm{~h}$ to the carbon-based nanomaterials according to the preparation described in the previous paragraph. The CytoTox-96® Non-Radioactive Cytotoxicity Assay (Promega) was used according to the manufacturer's instructions. Detection was performed using a microplate reader (Multiskan GO, Thermo Scientific) at 450 $\mathrm{nm}$. The activity of the released LDH was reported as a percentage of the total cellular LDH (measured after the complete lysis of control cells). 


\subsection{Pro-inflammatory response}

Tumor Necrosis Factor alpha (TNF- $\alpha)$ is one of the main pro-inflammatory cytokines produced by macrophages in an activation context. Cells were seeded in a second 96-well plate at 100000 cells/well and incubated for $24 \mathrm{~h}$ with the nanomaterials. TNF- $\alpha$ production was assessed by a commercial enzyme-linked immunosorbent assay kit (Quantikine ${ }^{\circledR}$ Mouse TNF- $\alpha$ /TNFSF1A Immunoassay, R\&D systems). The optical density was determined according to the manufacturer's instructions, using a microplate reader (Multiskan GO, Thermo Scientific) at $450 \mathrm{~nm}$. A standard curve was established and results were expressed in pg.mL $L^{-1}$ of TNF- $\alpha$.

\subsection{Oxidative stress}

The measurement of the broad spectrum of intracellular reactive oxygen species (ROS) gave an indicative assessment of the oxidative stress using the specific fluorescent probe DCFHDA DCF (2',7'-dichlorodihydrofluorescein diacetate). The OxiSelect ${ }^{\mathrm{TM}}$ Intracellular ROS Assay Kit (Cell Biolabs) was used according to the manufacturer's instructions. The fluorescence intensities were read at $530 \mathrm{~nm}$ emission with a $480 \mathrm{~nm}$ excitation (Fluoroskan Ascent, Thermo scientific). However, to avoid biased decreases of the fluorescence by the black carbon-based nanomaterials, a correction was applied. This correction is based on acellular standard curves of the fluorescent probe DCF (2',7'-dichlorofluorescein) for each nanomaterial and each dose (see supplementary material Figure A2 and Table A2). Results are presented as a percentage of the ROS produced by cells which were not exposed to carbon-based nanomaterials. A positive control was added which corresponds to cells exposed to $1 \mathrm{mM}$ of $\mathrm{H}_{2} \mathrm{O}_{2}$.

\subsection{Cell morphology}


A $24 \mathrm{~h}$ exposure of the cells to the smallest doses of CNT $\left(15 \mu \mathrm{g} \cdot \mathrm{mL}^{-1}\right)$ was conducted directly on an 8-well chambered coverglass (Lab-Tek®, Sigma-Aldrich). The cells were then rinsed twice with PBS, dried and conserved at $-20^{\circ} \mathrm{C}$ before a May-Grünwald Giemsa staining (MGG) with a Leica Auto Stainer XL. The stained cells were the observed by optical microscopy (Leica ICC50 HD, Leica Microsystems) at different magnifications and pictures were captured thank to the software Lasez (Leica Microsystems).

\subsection{Statistical analysis}

Results were expressed as the mean of three independent experiments, each carried out in triplicates, with standard errors of the mean value. Statistical significance was declared when $\mathrm{p}<0.05$ using a Student test with Tanagra software (Rakotomalala, 2005).

\section{RESULTS}

\section{Physicochemical characterization of carbon-based nanomaterials}

The three types of carbon-based nanomaterials exhibited different shapes with one nanometric dimension for the nano-graphite (NG), two for the carbon nanotubes (CNT) and three for the carbon black (CB) (Figure 1). 


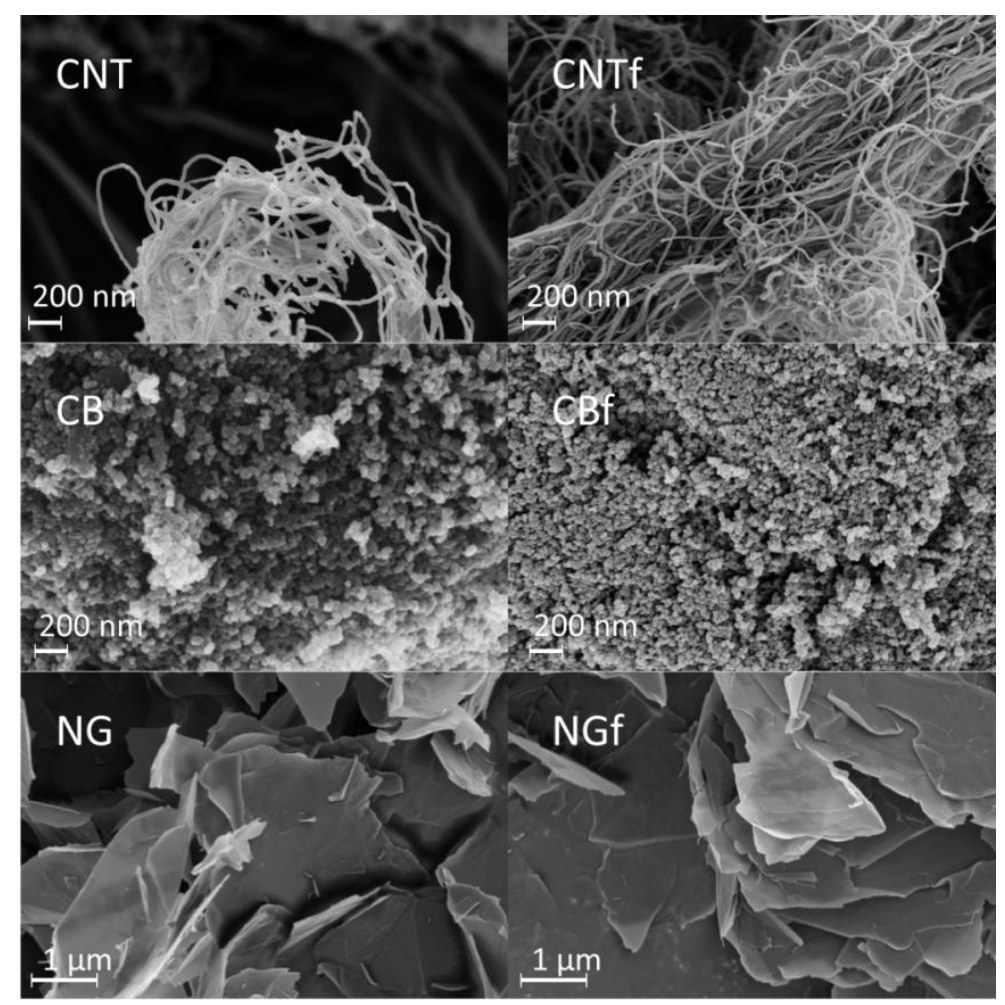

Figure 1: Scanning electron microscopy images of pristine and functionalized carbon-based nanomaterials. Pristine and functionalized carbon nanotubes (CNT and CNTf), pristine and functionalized carbon black (CB and $\mathrm{CBf}$ ), and pristine and functionalized Nano-graphite (NG and NGf).

The Table 1 summarizes the physicochemical characteristics of the pristine and functionalized carbon-based nanomaterial. The nanometric dimensions have been measured either with the scanning electron microscopy (SEM) for CNT and CB diameters or with atomic force microscopy (AFM) for NG thickness. While the nanomaterial shape remained alike, CNT and CB mean diameters decreased after acid functionalization due to the acid attack. On the contrary, the mean thickness of NG increased after acid functionalization. This and the strong decrease of the specific surface area (SSA) of acid functionalized NG (NGf) will be further discussed and may be explained by a change in aggregation and also porosity in the case of SSA. On the contrary, CB and CNT SSA remained at comparable levels after functionalization. Acid functionalization is also known to increase structural disorder. It has 
been confirmed for acid functionalized CNT and NG (CNTf and NGf) by Raman spectroscopy, looking at the Id/Ig intensity ratio. Raman spectra are displayed in the supplementary material (Figure A3). The results for $\mathrm{CB}$ and $\mathrm{CBf}$ are not reliable as it is not a crystallized form of carbon. Acid functionalized carbon-based nanomaterials were moreover purified from metallic catalysts. It is mainly remarkable for $\mathrm{CNT}$ as the Al level was almost 5 wt $\%$ before functionalization. However, it has to be noticed that pristine $\mathrm{NG}$ showed a Fe level of $0.15 \mathrm{wt} \%$ similar to the $\mathrm{CNT}$ one. After functionalization it decreased to 0.02 and $0.05 \mathrm{wt} \%$ for NGf and CNTf respectively confirming the purification by the acid treatment. 
Table 1: Physicochemical features of the six studied carbon-based nanomaterials.

\begin{tabular}{|l|l|l|l|l|l|l|}
\hline Sample & CNT & CNTf & CB & CBf & NG & NGf \\
\hline $\begin{array}{l}\text { Mean diameter } \\
\text { or thickness } \\
\text { (nm) }\end{array}$ & $23 \pm 4$ & $16 \pm 5$ & $42 \pm 10$ & $31 \pm 8$ & $20 \pm 9$ & $27 \pm 12$ \\
\hline SSA $\left(\mathbf{m}^{2} \mathbf{. g}^{-1}\right)^{\mathbf{A}}$ & $317 \pm 2$ & $279 \pm 1$ & $184 \pm 1$ & $186 \pm 2$ & $100 \pm 3$ & $27 \pm 0$ \\
\hline $\begin{array}{l}\text { Structural } \\
\text { disorder } \\
\text { (Id/Ig) }\end{array}$ & 0.82 & 1.83 & $0.98^{\mathrm{B}}$ & $0.81^{\mathrm{B}}$ & 0.14 & 0.23 \\
\hline $\begin{array}{l}\text { Catalytic } \\
\text { impurities } \\
\text { (wt\%) } \\
\text { Fe } \\
\begin{array}{l}\text { Al } \\
\text { Co }\end{array}\end{array}$ & 0.15 & 0.05 & 0.01 & 0.01 & 0.15 & 0.02 \\
\hline O (atomic \%) & 2 & 0.03 & 0.05 & 0.00 & 0.00 & 0.00 \\
\hline $\begin{array}{l}\text { Zeta potential } \\
\text { (mV) in water }\end{array}$ & $-9 \pm 8$ & $-48 \pm 2$ & $-25 \pm 9$ & $-35 \pm 6$ & $-23 \pm 3$ & 0.00 \\
\hline $\begin{array}{l}\text { Isoelectric } \\
\text { point (pH) in } \\
\text { water }\end{array}$ & $4.3 \pm 0.9$ & $<1.5$ & $3.2 \pm 0.4$ & $1.9 \pm 0.1$ & $1.9 \pm 0.1$ & $<1.5$ \\
\hline
\end{tabular}

${ }^{\mathrm{A}}$ : SSA : specific surface area, ${ }^{\mathrm{B}}$ : CB and CBf not well crystallized so the measure is

uncertain.

The presence of oxygen-containing groups was assessed by X-ray photoelectron spectroscopy (XPS), zeta potential and isoelectric points (pI) (Table 1) and by thermal desorption (Figure 2). The duration of the acid treatment, and the ratio of carbon-based nanomaterial and acids were optimized to obtain a similar level of functionalization. $\mathrm{C}_{1 \mathrm{~s}}$ and $\mathrm{O}_{1 \mathrm{~s}}$ peaks from the XPS spectra allowed the calculation of oxygen atomic percentages which reached 13 or $14 \%$ after functionalization. Before functionalization, the level of oxygen was higher for $\mathrm{CB}$ and $\mathrm{NG}(8 \%)$ than for $\mathrm{CNT}(2 \%)$ stating that these pristine nanomaterials presented more oxygen-containing groups. Zeta potentials in water decreased to below -30 $\mathrm{mV}$ after functionalization, indicating an increased stability (ISO - International Organization for Standardization, 2000, p. 200). Zeta potentials are very dependent of the $\mathrm{pH}$ of the suspensions, whereas $\mathrm{p} I$ are considered to avoid this approximation. All acid functionalized 
carbon-based nanomaterials exhibited $\mathrm{p} I$ under 1.9. However, the levels were different for pristine nanomaterials. As for the XPS value, the pristine CNT seemed to present less oxygencontaining groups as its $\mathrm{p} I$ was relatively high (4.3). The $\mathrm{p} I$ value for $\mathrm{CB}$ is not far from the CNT one (3.2). However, it seemed that the level of oxygen-containing groups of NG was already high before functionalization, according to its very low $\mathrm{p} I$ value (1.9). This was confirmed by the thermal desorption spectra. $\mathrm{CO}$ and $\mathrm{CO}_{2}$ desorption were followed during the heat treatment of the carbon-based nanomaterials. Oxygen-containing groups are expected to be desorbed and decomposed mainly in $\mathrm{CO}$ and $\mathrm{CO}_{2}$ gases. The masses corresponding to $\mathrm{H}_{2} \mathrm{O}_{2}, \mathrm{O}$, NO and $\mathrm{NO}_{2}$ were also followed and showed the same trends at lower levels (data not shown). Significantly higher levels of $\mathrm{CO}$ and $\mathrm{CO}_{2}$ were desorbed for CNTf and $\mathrm{CBf}$ compared to CNT and CB. The difference was smaller for NG. It thus confirmed that NG had already a high level of oxygen-containing groups before functionalization. 

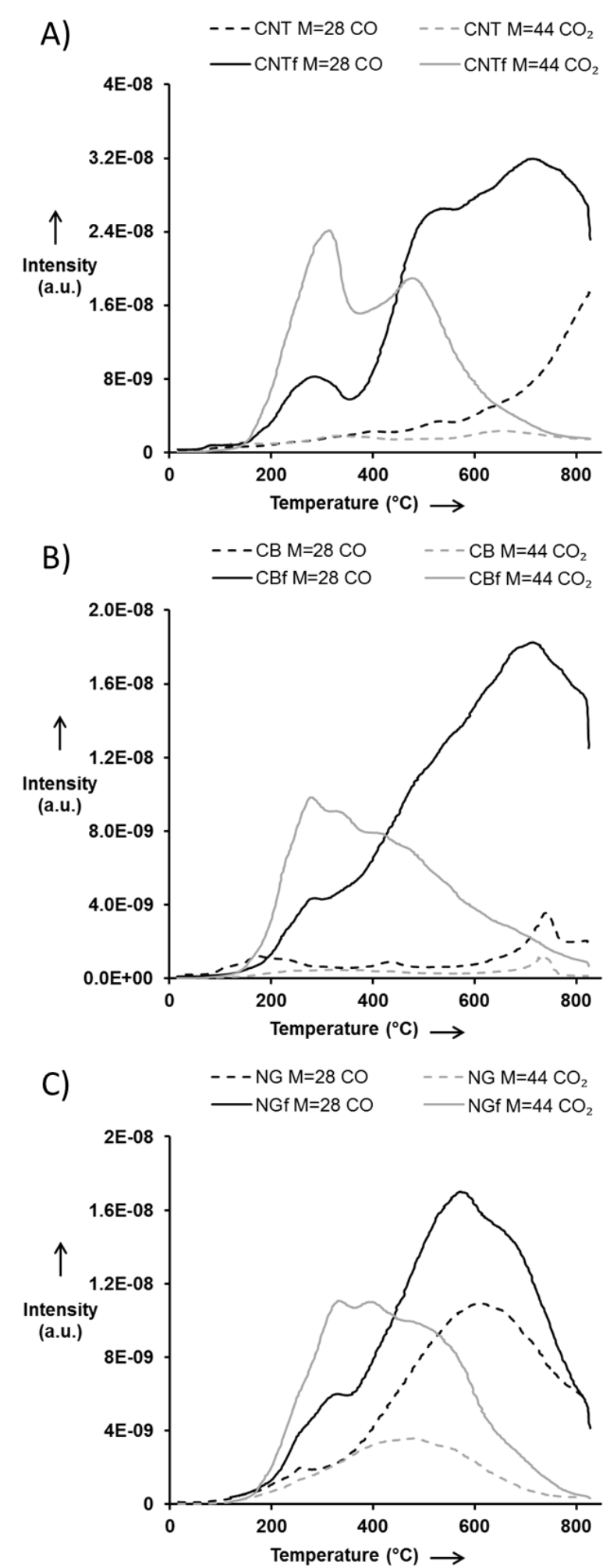

Figure 2: Thermal desorption of $\mathrm{CO}$ and $\mathrm{CO}_{2}$ from pristine and functionalized carbon-based nanomaterials. A) pristine and functionalized carbon nanotubes (CNT and CNTf), B) pristine and functionalized carbon black (CB and $\mathrm{CBf}$ ), and $\mathrm{C})$ pristine and functionalized nanographite (NG and NGf). 


\section{In vitro toxicity assays on RAW 264.7 macrophages}

The in vitro toxicity of the six carbon-based nanomaterials was assessed on a murine macrophage cell line (RAW 264.7). This cell line is widely studied, robust and allows repeatable results. Three different cellular and molecular responses were studied. LDH release informed about the cytotoxicity induced by a $24 \mathrm{~h}$ exposure to carbon-based nanomaterials. The production of the cytokine TNF- $\alpha$ (tumor necrosis factor $\alpha$ ) informed about the proinflammatory activity after a $24 \mathrm{~h}$ exposure to carbon-based nanomaterials. ROS production is directly related to oxidative stress, with a shorter activation, so with an evaluation after only 90 min of exposure to carbon-based nanomaterials. Lastly, the cell morphology was observed after $24 \mathrm{~h}$ of contact with carbon-based nanomaterials and a MGG (May-Grünwald Giemsa) staining.

\subsection{Biological impact of the acid functionalization}

Significant LDH releases were only found for the highest dose of CNT, NG and NGf (Figure 3). For NG and NGf, the LDH release seemed however to follow a dose-dependent trend. There was no significant difference in the LDH when comparing the pristine and functionalized carbon-based nanomaterials. Thus, no impact of acid functionalization was shown whatever the carbon-based nanomaterials. 


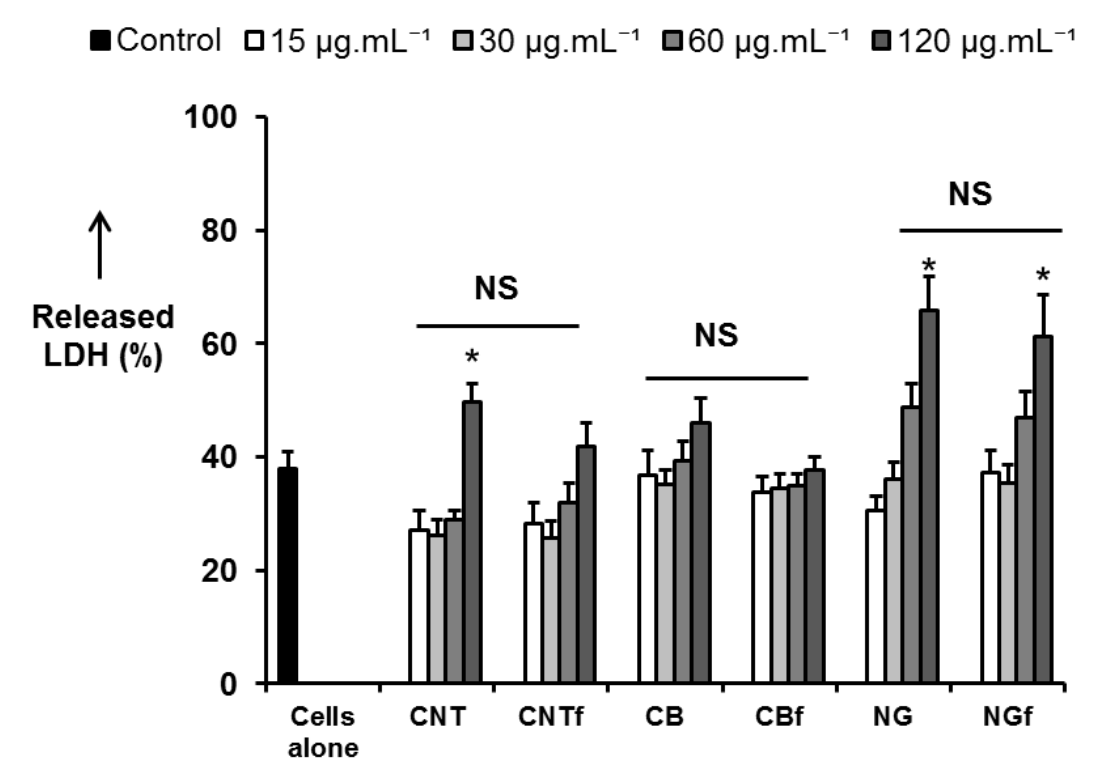

Figure 3: Impact of the acid functionalization of carbon-based nanomaterials on the cytotoxicity. NS: not significant. The cytotoxicity was determined by LDH release after a 24 $\mathrm{h}$ exposure. Results are reported to the total cellular LDH measured after lysis of control cells. $(\mathrm{n}=3, *$ : significantly higher than the negative control, $\mathrm{p}<0.05, \mathrm{NS}$ : difference not significant between pristine and acid functionalized nanomaterials)

Figure 4 displays the level of TNF- $\alpha$ after an exposure to the different carbon-based nanomaterials. CNT and NG induced significant pro-inflammatory response at $120 \mu \mathrm{g} . \mathrm{mL}^{-1}$, while CNTf and NGf induced a significant response as soon as 60 and $30 \mu \mathrm{g} \cdot \mathrm{mL}^{-1}$ respectively with a dose dependent effect. $\mathrm{CB}$ and $\mathrm{CBf}$ showed no sign of pro-inflammatory enhancement. 


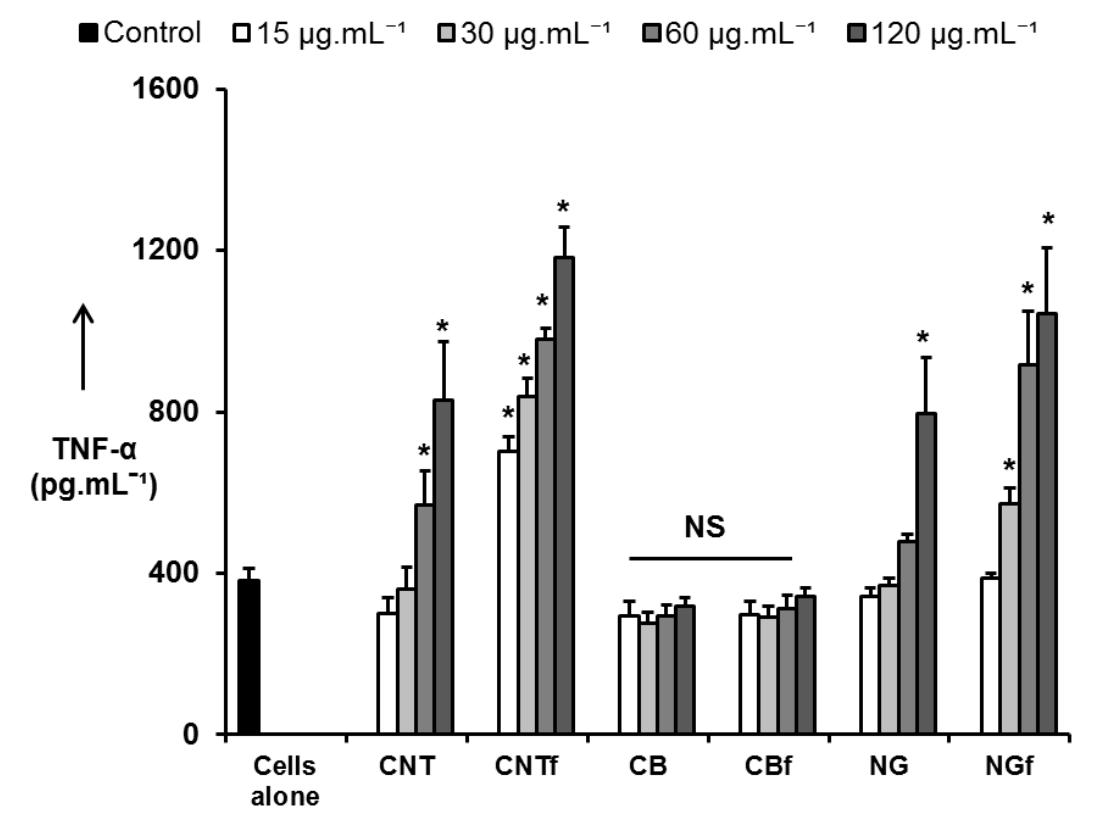

Figure 4: Impact of the acid functionalization of carbon-based nanomaterials on the proinflammatory response. The pro-inflammatory activity was evaluated by the level of TNF- $\alpha$ after a 24 h exposure. $(n=3$, *: significantly higher than the negative control, $p<0.05$, NS: difference not significant between pristine and acid functionalized nanomaterials). All pristine carbon-based nanomaterials enhanced ROS production in a dose-dependent manner (Figure 5). ROS levels for $120 \mu \mathrm{g} \cdot \mathrm{mL}^{-1}$ of CNT and CB reached three to four times and two times the level of the positive control respectively. The levels of ROS production were however strongly reduced after functionalization for all types of carbon-based nanomaterials. 


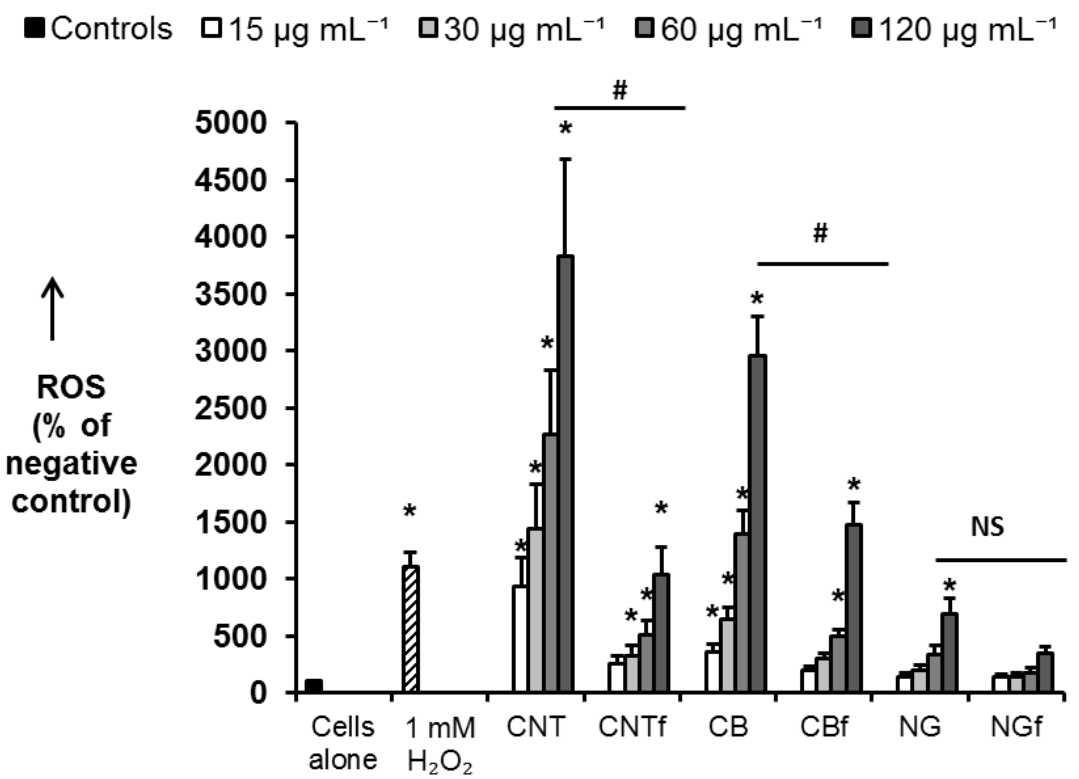

Figure 5: Impact of the acid functionalization of carbon-based nanomaterials on the oxidative stress. Oxidative stress was determined by ROS production after a 90 min exposure. Results are expressed as a percentage of the negative control. $(n=3$, *: significantly higher than the negative control, \#: significantly different between the pristine and functionalized nanomaterials, NS: difference not significant between pristine and acid functionalized nanomaterials $\mathrm{p}<0.05)$.

\subsection{Comparison of the carbon-based nanomaterials biological impacts}

Comparing acid functionalized surface allowed to get rid of the difference in the level of oxygen-containing groups and the content of metallic impurities. The influence of the different SSA was moreover eliminated when looking at the cellular response with doses expressed in surface rather than in mass. The question of dose metric is indeed crucial. The toxicity of a nanomaterial could correlate best with their available surface than with their mass, volume or number (Oberdörster et al., 1992).

At comparable surface, $\mathrm{NGf}$ exhibited a stronger cytotoxic response than $\mathrm{CNTf}$ and $\mathrm{CBf}$ (Figure 6). NGf showed also the highest pro-inflammatory response, followed by CNTf 
(Figure 7). CBf induced no cytotoxic and pro-inflammatory response. However, it enhanced an oxidative stress similar to CNTf and NGf (Figure 8). MGG observations allowed observing preferential interaction of the carbon-based nanomaterials with the macrophages (Figure 9). This technique does not permit to affirm that the nanomaterials were uptaken. It is not possible to make a difference between internalized nanomaterials and those just adhered at the cell surface. However, it was noticeable that all CBf seemed to interact with the macrophages, while agglomerates and aggregates of CNTf and NGf were found free in the medium. Regarding its small dimensions, CBf is likely to be fully internalized, unlike NG and CNT.

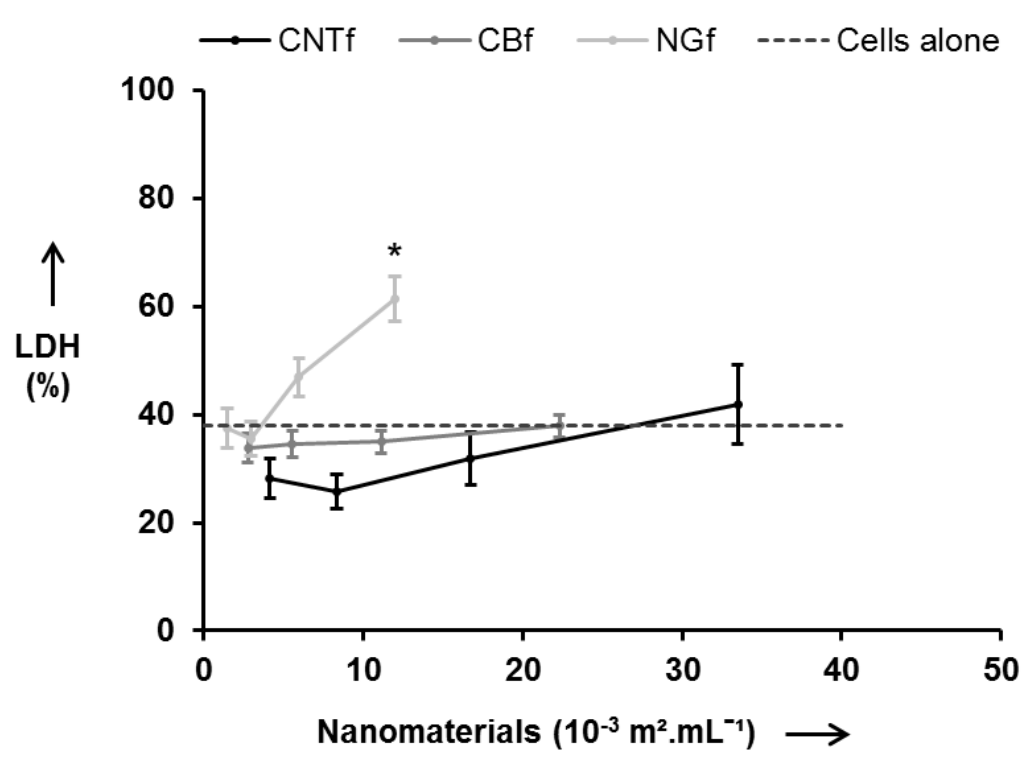

Figure 6: Impact of the morphology on the cytotoxicity of carbon-based nanomaterials.

Doses were expressed in unit of acid functionalized surface. The cytotoxicity was determined by $\mathrm{LDH}$ release after a $24 \mathrm{~h}$ exposure. Results are reported to the total cellular LDH measured after lysis of control cells. ( $n=3, *$ : significantly higher than the negative control, $p<0.05)$. 


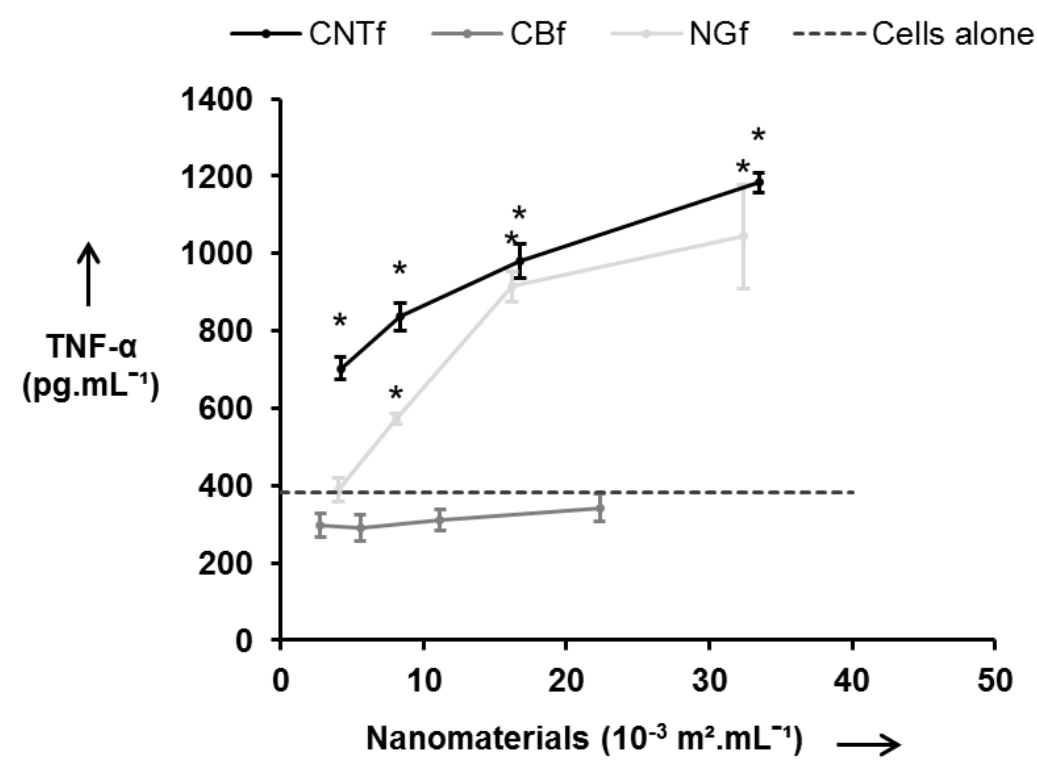

Figure 7: Impact of the morphology on the pro-inflammatory response to carbon-based nanomaterials. Doses were expressed in unit of acid functionalized surface. The proinflammatory activity was evaluated by the level of TNF- $\alpha$ after a $24 \mathrm{~h}$ exposure. $(\mathrm{n}=3, *$ : significantly higher than the negative control, $\mathrm{p}<0.05)$.

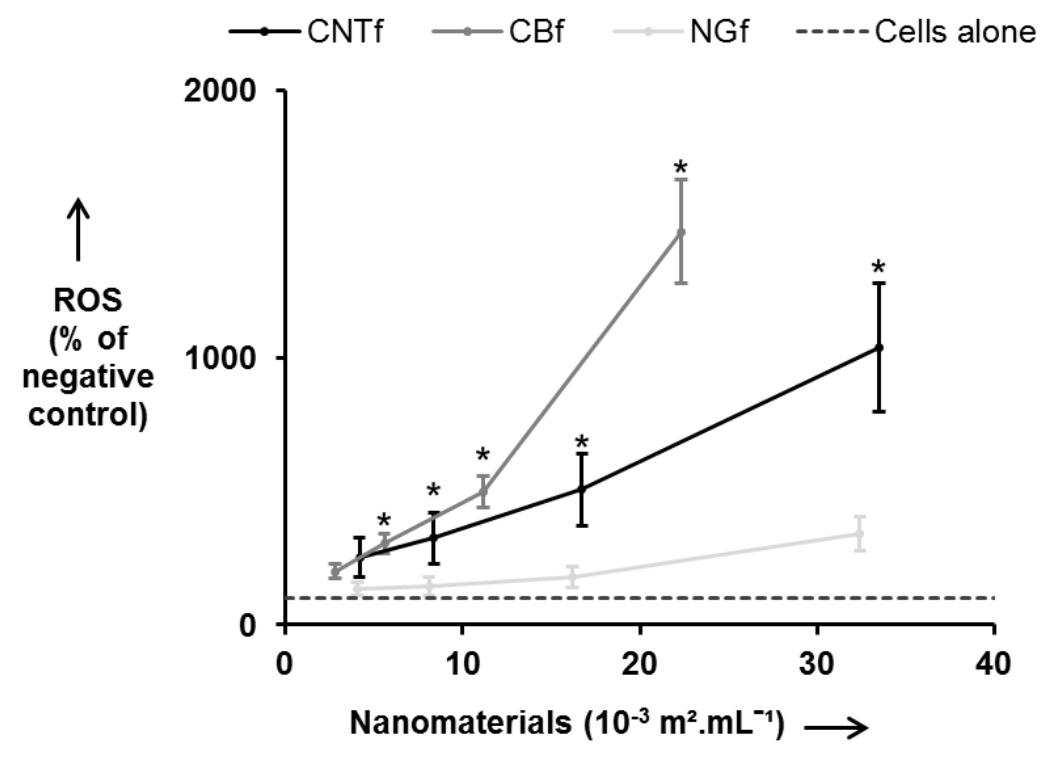

Figure 8: Impact of the morphology on the oxidative stress enhanced by carbon-based nanomaterials. Doses were expressed in unit of acid functionalized surface. Oxidative stress was determined by ROS production after a 90 min exposure. Results are expressed as a 
percentage of the negative control. ( $n=3$, *: significantly higher than the negative control, $\mathrm{p}<0.05)$.

The comparison of the effects between pristine and functionalized nanomaterials in terms of surface area is reported in Supplementary material Figure A4.

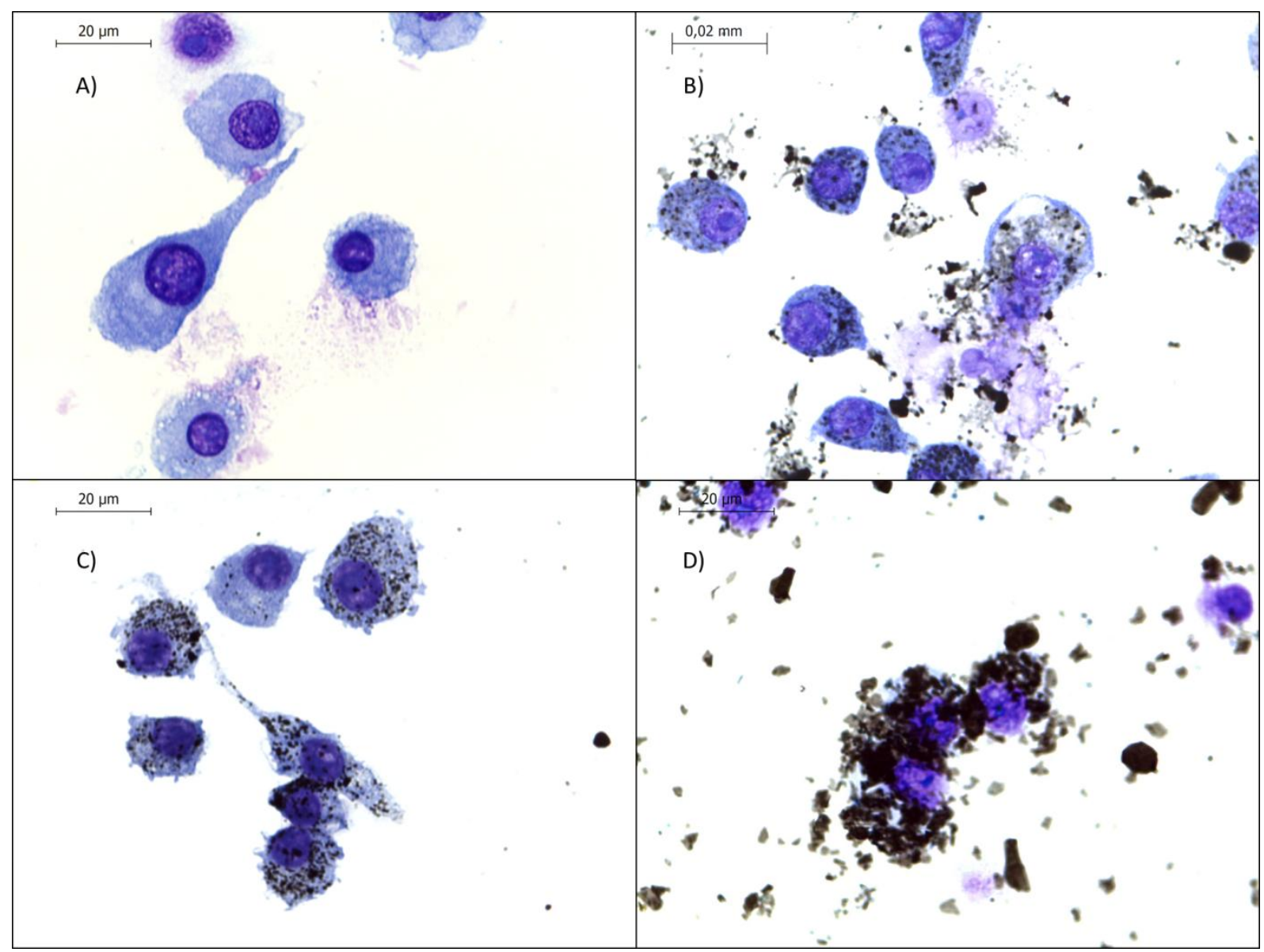

Figure 9: Microscopic images of RAW 264.7 cells exposed for $24 \mathrm{~h}$ to $15 \mu \mathrm{g} . \mathrm{mL}-1$ of carbonbased nanomaterials after a May-Grünwald-Giemsa staining. A) negative control: cells alone, B) functionalized carbon nanotubes (CNTf), C) functionalized carbon black (CBf), and D) functionalized nano-graphite (NG).

\section{DISCUSSION}

\section{Physicochemical impacts of the acid functionalization of carbon-based} nanomaterials 
This study compares the biological properties of three types of carbon-based nanomaterials, NG, CNT and CB, showing one, two and three nanometric dimensions of the same order of magnitude respectively. The non-nanometric dimensions of CNT and NG were not experimentally confirmed due to the difficulties to measure entangled CNT or agglomerated NG flakes (mean length and mean flake diameter were 1.5 and $4.5 \mu \mathrm{m}$ according to the producers). At first sight, looking at the electron microscopy images, the acid functionalization did not seem to impact the carbon-based nanomaterials morphology. However, it affected some of the physicochemical features of the carbon-based nanomaterials. All carbon-based nanomaterials were purified by the acid functionalization. The metallic impurities were indeed dissolved in the strong acids (Hamilton et al., 2013; Kim et al., 2014). Mean diameters of CNT and NG were decreased as the surface underwent the acid attack. As shown for CNT (Hu et al., 2003), this same acid attack led to an increase in structural defects observed for CNTf and NGf. However, it was unfortunately not visible for CBf due to the already low crystallization of CB. NG seemed to follow a different trend when considering the increase of its mean thickness after functionalization. It is, though, not significant unlike the strong decrease in SSA. The sample was thoroughly dried, and the measurement was repeated several times, thus this diminution is not believed to be due to an excess of hydration. The SSA reduction almost by 4 of NGf could be explained by differences in agglomeration and structure caused by acid functionalization. The phenomenon could be close to the one suggested by Wang et al. (Wang et al., 2014). These authors witnessed a change in microporosity and mesoporosity of reduced $\mathrm{NG}$ after $\mathrm{KOH}$ activation. While reduced NG consisted of carbon sheets with stacked carbon layers, the $\mathrm{KOH}$ treatment separated them into smaller and thinner sheets. They gathered into large and highly porous structures due to partial interstacking. The resulting available external surface area was significantly smaller than the surface of the small compact agglomerates of reduced NG. It 
has to be underlined, however, that this phenomenon affects only dried powder. In aqueous media, such as the cell culture media, the dispersion is expected to be higher for functionalized carbon-based nanomaterials due to the surface oxygen-containing groups. This was indeed confirmed by the lower zeta potentials and $\mathrm{p} I$.

It has been pointed out that the levels of oxygen-containing groups were different between the pristine carbon-based nanomaterials. Pristine CNT seemed to contain the lowest level of oxygen-containing groups according to XPS, $\mathrm{p} I$ and thermal desorption measurements. Pristine CB showed a medium level of surface oxygen-containing groups. Lastly, pristine NG exhibited a similar atomic percentage of $\mathrm{O}$ to $\mathrm{CB}$ according to the XPS measurement, but a higher level of oxygen-containing groups according to $\mathrm{p} I$ and thermal desorption. As XPS analyzes the extreme surface, it may miss some oxygen-containing groups linked with the deeper carbon layers. After functionalization, the level of oxygen-containing groups linked with a decrease in hydrophobicity seemed to be equalized between CNTf, CBf and NGf, but could be partially underestimated for NGf for the same reason.

\section{Biological impact of the acid functionalization of carbon-based nanomaterials}

Our previous study (Figarol et al., 2014) has demonstrated that acid functionalization of carbon nanotubes has a weak impact on cytotoxicity, increased the pro-inflammatory response and decreased the oxidative stress. In this study we showed that the in vitro impact on macrophages response to acid functionalization followed the same trend for three types of carbon-based nanomaterials. Little impact on the cytotoxicity was detected, the only responses were at the highest dose of CNT and NG with possibly a slight decrease for CNTf and NGf but not significant. An increase in TNF- $\alpha$ production was observed for CNTf and NGf. It was not observed for CBf, which may be linked with the absence of pro-inflammatory response for the pristine $\mathrm{CB}$. The increase for CNTf and NGf might be due to the difference 
in surface chemistry. The change in surface charge and decrease in hydrophobicity could indeed impact the adsorbed proteins on the surface of the carbon-based nanomaterial. This protein layer constitutes the corona which can influence the cellular interactions with a carbon-based nanomaterial (Lynch and Dawson, 2008). A second assumption to explain the increase of the pro-inflammatory response is the increased available surface for cell interactions. Functionalized carbon-based nanomaterials are indeed expected to present a greater dispersibility in the aqueous culture medium, which could increase the cell response (Wang et al., 2010). On the other hand, ROS production was largely decreased after functionalization of the three carbon-based nanomaterials. For CNT mainly and NG secondly, this can be due to the purification from metallic catalysts. Transition metals such as $\mathrm{Fe}$ and $\mathrm{Al}$ indeed contribute to ROS production notably by the involvement in the Fenton reaction (Ge et al., 2012; Ruipérez et al., 2012). However, as the response was still significant for purified carbon-based nanomaterials, another source of oxidative stress is involved. Direct interaction between carbon-based nanomaterials and the cells could indeed enhance an oxidative stress. A third mechanism should be mentioned, corresponding to the scavenging capacity. Carbonbased nanomaterials have indeed the potential to reduce the level of oxygenated free radicals in the medium, through surface adsorption or other physicochemical reactions not well understood for now, but increasing with the level of structural defects (Fenoglio et al., 2006; Galano et al., 2010; Martinez et al., 2010). Acid functionalization increased the structural disorder, so the scavenging activity could explain the decrease in ROS production after functionalization for all three nanomaterials.

When addressing the question of nanomaterials toxicity, it is important to consider the potential artifacts. It is indeed now well-known that nanomaterials especially carbon-based nanomaterials can interfere with common toxicity tests (Casey et al., 2007, 2007; Dusinska et al., 2015; Monteiro-Riviere et al., 2009). We have shown that the assay measuring ROS 
production was biased, thus a correction based on controls without cells has been used (see supplementary material Figure A2 and Table A2). In a previous work (Forest et al., 2015) we assessed the biases caused by CNT on the LDH assay. Despite two types of biases, the test was still considered as reliable, as these biases almost compensated and had no significant impact on the conclusion. Adsorption of TNF- $\alpha$ on carbon-based nanomaterials could occur. It has been showed for hydrophilic CNT by Leshuai W Zhang, (2007) and for other noncarbon-based nanomaterials (Guadagnini et al., 2015; Pailleux et al., 2013). It could lead to an underestimation of the TNF- $\alpha$ level. However the differences between the TNF- $\alpha$ concentrations for CNT and CNTf, and NG and NGf were important and we do not believe that they could be due uniquely to a difference in biases of the TNF- $\alpha$ test.

Other studies on the subject tend to be contradictory. Several studies seemed to conclude also at an increase in macrophage pro-inflammatory response after CNT acid functionalization (Dong et al., 2012; Wang et al., 2012; Zhang et al., 2012). Few data are available concerning oxidative stress, but some studies on NG suggested also a decrease induced by higher levels of oxygen-containing groups (Duch et al., 2011; Sasidharan et al., 2012, 2011). The last one however concluded at an increase in the pro-inflammatory response after reducing oxidized NG. The cell line and the conditions of exposure were nevertheless different from our study. Tong et al. (Tong et al., 2009) studied simultaneously the in vivo impacts of pristine and acid functionalized SWCNT and CB after oropharyngeal aspiration of 10 to $40 \mu \mathrm{g}$ of nanomaterial per mouse. They found an increase in pulmonary toxicity (both cytotoxicity and inflammation) induced by the functionalization. Our results indicated only an increase in the pro-inflammatory response, but the cytotoxicity levels were already very low for pristine nanomaterials. It would be interesting to compare our powders and those from Tong et al. for an equivalent exposure and a similar experimental design (to avoid the comparison of in vitro and in vivo experiments). 


\section{Comparison of carbon-based nanomaterials biological impacts}

Table 2: Summary, morphological impact on the cellular response of carbon-based nanomaterials showing comparable surface. -: low response, + : high response, ++ : very high response

\begin{tabular}{|l|l|l|l|}
\hline Cellular response & CNTf & CBf & NGf \\
\hline Cytotoxicity (LDH) & - & - & + \\
\hline $\begin{array}{l}\text { Pro-inflammatory } \\
\text { (TNF-a) }\end{array}$ & + & - & ++ \\
\hline $\begin{array}{l}\text { Oxidative stress } \\
\text { (ROS) }\end{array}$ & + & + & - \\
\hline
\end{tabular}

The cellular impacts of the different carbon-based nanomaterials have been studied with comparable available surface for cell interactions and close surface chemistry. Looking at the results expressed in surface area and not in mass allowed a better differentiation of the cell responses induced by the three carbon-based nanomaterials. Acid functionalization was used as a way to equilibrate the level of oxygen-containing groups and to remove the impurities, so that the differences in surface chemistries were minimized. Table 2 sums up the comparative results of the in vitro response to CNTf, CBf and NGf. NGf evidenced the highest cellular response. CNTf led to a high pro-inflammatory response and oxidative stress but a low cytotoxicity. $\mathrm{CBf}$ induced the lowest biological response: no cytotoxicity, low inflammation and equivalent oxidative stress. These differences may be due to the difference in morphology and nanometric dimension. The higher response to NGf and CNTf could be related to a platelet or a fiber effect (Schinwald et al., 2011; Tran et al., 2011). Donaldson et al. (Donaldson et al., 2010) explained the classical fiber paradigm as an understanding of three 
main properties of a nanofiber: biopersistent so that it creates accumulation, thin enough so that its small aerodynamic diameter enable deposition beyond the ciliated airways, and long enough so that it is difficult to be effectively cleared and for macrophages to phagocyte it. The microscopic observations of the cells interacting with carbon-based nanomaterials reinforced this hypothesis. Almost no $\mathrm{CBf}$ remained free in the culture medium, while only part of the NGf and CNTf interacted with the macrophages. Similar trends were also seen for pristine carbon-based nanomaterials (Supplementary material Figure A5). Internalization should be easier for round shaped $\mathrm{CBf}$ with nanometric dimension, than for the fiber or platelets with one or two micrometric dimensions. However, no sign of frustrated phagocytosis was clearly observed. When macrophages fail to fully engulf long and rigid CNT or oversized NG platelets, this can indeed lead to frustrated phagocytosis (Brown et al., 2007). Macrophages are then seen activated, too large nanomaterials can distort the macrophage cytoplasm, rosette-like formation of macrophages or giant cells can be seen around large nanomaterials (Fraczek-Szczypta et al., 2012; Schinwald et al., 2011). As frustrated phagocytosis enhances the pro-inflammatory response and oxidative stress, this could have been a further explanation for the higher cellular response to NGf and CNTf. The study of Zhang et al. (Zhang et al., 2012) displayed a similar cytotoxicity and oxidative stress of HeLa cells to functionalized MWCNT and oxidized NG. However, the cytotoxicity varied according to the used assay. They confirmed moreover that only part of the carbon-based nanomaterials were internalized or tightly bound to the cell membrane. Another explanation for the lowest cellular response to CBf could be its lower crystallinity. It has indeed been shown for nanoparticles such as silica that the crystalline forms trigger higher inflammation and lead to more pathogenicity than amorphous nanoparticles (Fubini et al., 1999; Perkins et al., 2012; Sandberg et al., 2012). Graphene-like structures are made of hybridized $\mathrm{sp}^{2}$ carbons, or $\mathrm{sp}^{3}$ carbons linked with the structural defects. CNT and NG are based on this structure and demonstrate a higher chemical 
reactivity than $\mathrm{CB}$. However, $\mathrm{CNTf}, \mathrm{CBf}$ and NGf exhibited functionalized groups at their surface that should mask and minimize the impact of the difference in crystallinity.

\section{CONCLUSIONS}

This physicochemical and toxicological study was designed with two main objectives: the determination of the cellular impact of the acid functionalization of three different carbonbased nanomaterials, and the cellular impact of these nanomaterials morphology at equivalent surface chemistry. It was demonstrated that acid functionalization has the same impact whatever the carbon-based nanomaterials: no significant impact on cytotoxicity, enhancement of the pro-inflammatory response, and a decrease in oxidative stress. Carbon black however made an exception, as no pro-inflammatory response was seen before or after functionalization. At a similar dose in surface and a similar surface chemistry, nano-graphite showed higher cellular response than carbon nanotubes and even higher than carbon black. Further investigations have to be carried out to determine if there is a link with the internalization mechanisms and possible frustrated phagocytosis. Carbon-based nanomaterials do not have the same toxicity potential according to their morphology and crystallinity, and it has to be pointed out that the safest one here is considered as a possible carcinogenic to humans. This emphasized the need for further studies on the toxicity of carbon nanotubes and graphene, especially their impacts for a long-term exposure.

\section{ACKNOWLEDGMENTS}

The authors would like to thank Yoann Garnier and Vincent Barnier from the structure and material center (EMSE) for their help regarding the XPS and AFM measurements, and Guy Tournier for his help regarding the thermal desorption analyses.

\section{CONFLICT OF INTEREST}


The authors have no conflict of interests to declare. All authors have approved the final version of this manuscript and its submission.

\section{REFERENCES}

Belin, T., Epron, F., 2005. Characterization methods of carbon nanotubes: a review. Mater. Sci. Eng. B-Solid State Mater. Adv. Technol. 119, 105-118. doi:10.1016/j.mseb.2005.02.046

Belyanskaya, L., Manser, P., Spohn, P., Bruinink, A., Wick, P., 2007. The reliability and limits of the MTT reduction assay for carbon nanotubes-cell interaction. Carbon 45, 2643-2648. doi:10.1016/j.carbon.2007.08.010

Bottini, M., Bruckner, S., Nika, K., Bottini, N., Bellucci, S., Magrini, A., Bergamaschi, A., Mustelin, T., 2006. Multi-walled carbon nanotubes induce T lymphocyte apoptosis. Toxicol. Lett. 160, 121-126. doi:10.1016/j.toxlet.2005.06.020

Brown, D.M., Kinloch, I.A., Bangert, U., Windle, A.H., Walter, D.M., Walker, G.S., Scotchford, C.A., Donaldson, K., Stone, V., 2007. An in vitro study of the potential of carbon nanotubes and nanofibres to induce inflammatory mediators and frustrated phagocytosis. Carbon 45, 1743-1756. doi:10.1016/j.carbon.2007.05.011

Casey, A., Herzog, E., Davoren, M., Lyng, F.M., Byrne, H.J., Chambers, G., 2007. Spectroscopic analysis confirms the interactions between single walled carbon nanotubes and various dyes commonly used to assess cytotoxicity. Carbon 45, $1425-$ 1432. doi:10.1016/j.carbon.2007.03.033

Chen, B., Liu, Y., Song, W.M., Hayashi, Y., Ding, X.C., Li, W.H., 2011. In Vitro Evaluation of Cytotoxicity and Oxidative Stress Induced by Multiwalled Carbon Nanotubes in Murine RAW 264.7 Macrophages and Human A549 Lung Cells. Biomed. Environ. Sci. 24, 593-601. doi:10.3967/0895-3988.2011.06.002 
Di Giorgio, M.L., Bucchianico, S.D., Ragnelli, A.M., Aimola, P., Santucci, S., Poma, A., 2011. Effects of single and multi walled carbon nanotubes on macrophages: Cyto and genotoxicity and electron microscopy. Mutat. Res. Toxicol. Environ. Mutagen. 722, 20-31. doi:10.1016/j.mrgentox.2011.02.008

Donaldson, K., Murphy, F.A., Duffin, R., Poland, C.A., 2010. Asbestos, carbon nanotubes and the pleural mesothelium: a review of the hypothesis regarding the role of long fibre retention in the parietal pleura, inflammation and mesothelioma. Part. Fibre Toxicol. 7, 5. doi:10.1186/1743-8977-7-5

Dong, P.-X., Wan, B., Guo, L.-H., 2012. In vitro toxicity of acid-functionalized single-walled carbon nanotubes: Effects on murine macrophages and gene expression profiling. Nanotoxicology 6, 288-303. doi:10.3109/17435390.2011.573101

Duch, M.C., Scott Budinger, G.R., Liang, Y.T., Soberanes, S., Urich, D., Chiarella, S.E., Campochiaro, L.A., Gonzalez, A., Chandel, N.S., Hersam, M.C., Mutlu, G.M., 2011. Minimizing Oxidation and Stable Nanoscale Dispersion Improves the Biocompatibility of Graphene in the Lung. Nano Lett. 11, 5201-5207. doi:10.1021/nl202515a

Dusinska, M., Boland, S., Saunders, M., Juillerat-Jeanneret, L., Tran, L., Pojana, G., Marcomini, A., Volkovova, K., Tulinska, J., Knudsen, L.E., Gombau, L., Whelan, M., Collins, A.R., Marano, F., Housiadas, C., Bilanicova, D., Halamoda Kenzaoui, B., Correia Carreira, S., Magdolenova, Z., Fjellsbø, L.M., Huk, A., Handy, R., Walker, L., Barancokova, M., Bartonova, A., Burello, E., Castell, J., Cowie, H., Drlickova, M., Guadagnini, R., Harris, G., Harju, M., Heimstad, E.S., Hurbankova, M., Kazimirova, A., Kovacikova, Z., Kuricova, M., Liskova, A., Milcamps, A., Neubauerova, E., Palosaari, T., Papazafiri, P., Pilou, M., Poulsen, M.S., Ross, B., Runden-Pran, E., Sebekova, K., Staruchova, M., Vallotto, D., Worth, A., 2015. Towards an alternative 
testing strategy for nanomaterials used in nanomedicine: Lessons from NanoTEST. Nanotoxicology 9, 118-132. doi:10.3109/17435390.2014.991431

Fenoglio, I., Tomatis, M., Lison, D., Muller, J., Fonseca, A., Nagy, J.B., Fubini, B., 2006. Reactivity of carbon nanotubes: Free radical generation or scavenging activity? Free Radic. Biol. Med. 40, 1227-1233. doi:10.1016/j.freeradbiomed.2005.11.010

Figarol, A., Pourchez, J., Boudard, D., Forest, V., Tulliani, J.-M., Lecompte, J.-P., Cottier, M., Bernache-Assollant, D., Grosseau, P., 2014. Biological response to purification and acid functionalization of carbon nanotubes. J. Nanoparticle Res. 16, 1-12. doi:10.1007/s11051-014-2507-y

Forest, V., Figarol, A., Boudard, D., Cottier, M., Grosseau, P., Pourchez, J., 2015. Adsorption of Lactate Dehydrogenase Enzyme on Carbon Nanotubes: How to Get Accurate Results for the Cytotoxicity of These Nanomaterials. Langmuir 31, 3635-3643. doi:10.1021/acs.langmuir.5b00631

Fraczek-Szczypta, A., Menaszek, E., Syeda, T., Misra, A., Alavijeh, M., Adu, J., Blazewicz, S., 2012. Effect of MWCNT surface and chemical modification on in vitro cellular response. J. Nanoparticle Res. 14, 1-14. doi:10.1007/s11051-012-1181-1

Fubini, B., Zanetti, G., Altilia, S., Tiozzo, R., Lison, D., Saffiotti, U., 1999. Relationship between surface properties and cellular responses to crystalline silica: Studies with heat-treated cristobalite. Chem. Res. Toxicol. 12, 737-745. doi:10.1021/tx980261a

Galano, A., Francisco-Marquez, M., Martinez, A., 2010. Influence of Point Defects on the Free-Radical Scavenging Capability of Single-Walled Carbon Nanotubes. J. Phys. Chem. C 114, 8302-8308. doi:10.1021/jp101544u

Ge, C., Li, Y., Yin, J.-J., Liu, Y., Wang, L., Zhao, Y., Chen, C., 2012. The contributions of metal impurities and tube structure to the toxicity of carbon nanotube materials. NPG Asia Mater. 4, e32. doi:10.1038/am.2012.60 
Guadagnini, R., Halamoda Kenzaoui, B., Walker, L., Pojana, G., Magdolenova, Z., Bilanicova, D., Saunders, M., Juillerat-Jeanneret, L., Marcomini, A., Huk, A., Dusinska, M., Fjellsbø, L.M., Marano, F., Boland, S., 2015. Toxicity screenings of nanomaterials: challenges due to interference with assay processes and components of classic in vitro tests. Nanotoxicology 9 Suppl 1, 13-24. doi:10.3109/17435390.2013.829590

Hamilton, R.F., Wu, Z., Mitra, S., Shaw, P.K., Holian, A., 2013. Effect of MWCNT size, carboxylation, and purification on in vitro and in vivo toxicity, inflammation and lung pathology. Part. Fibre Toxicol. 10, 57. doi:10.1186/1743-8977-10-57

Hu, H., Zhao, B., Itkis, M.E., Haddon, R.C., 2003. Nitric acid purification of single-walled carbon nanotubes. J. Phys. Chem. B 107, 13838-13842. doi:10.1021/jp035719i

Hummers, W.S., Offeman, R.E., 1958. Preparation of Graphitic Oxide. J. Am. Chem. Soc. 80, 1339-1339. doi:10.1021/ja01539a017

IARC, 2010. Carbon Black, in: IARC Monographs on the Evaluation of Carcinogenic Risks to Humans, Carbon Black, Titanium Dioxide, and Talc. WHO Press, p. 149.

Iijima, S., 1991. Helical microtubules of graphitic carbon. Nature 354, 56-58. doi:10.1038/354056a0

Iijima, S., Ichihashi, T., 1993. Single-Shell Carbon Nanotubes of 1-Nm Diameter. Nature 363, 603-605. doi:10.1038/363603a0

ISO - International Organization for Standardization, 2000. ISO 14887:2000 Sample preparation - Dispersing procedures for powders in liquids, ISO 14887:2000.

ISO/TS 27687:2008, 2008. Nanotechnologies -- Terminology and definitions for nano-objects -- Nanoparticle, nanofibre and nanoplate.

Kim, J.-E., Kang, S.-H., Moon, Y., Chae, J.-J., Lee, A.Y., Lee, J.-H., Yu, K.-N., Jeong, D.H., Choi, M., Cho, M.-H., 2014. Physicochemical determinants of multi-walled carbon 
nanotubes on cellular toxicity: influence of synthetic method and post-treatment. Chem. Res. Toxicol. 27, 290-303. doi:10.1021/tx400397g

Lam, C.-W., James, J.T., McCluskey, R., Hunter, R.L., 2004. Pulmonary Toxicity of SingleWall Carbon Nanotubes in Mice 7 and 90 Days After Intratracheal Instillation. Toxicol. Sci. 77, 126-134. doi:10.1093/toxsci/kfg243

Leshuai W Zhang, L.Z., 2007. Biological interactions of functionalized single-wall carbon nanotubes in human epidermal keratinocytes. Int. J. Toxicol. 26, 103-13. doi:10.1080/10915810701225133

Lynch, I., Dawson, K.A., 2008. Protein-nanoparticle interactions. Nano Today 3, 40-47. doi:10.1016/S1748-0132(08)70014-8

Ma-Hock, L., Strauss, V., Treumann, S., Kuettler, K., Wohlleben, W., Hofmann, T., Groeters, S., Wiench, K., van Ravenzwaay, B., Landsiedel, R., 2013. Comparative inhalation toxicity of multi-wall carbon nanotubes, graphene, graphite nanoplatelets and low surface carbon black. Part. Fibre Toxicol. 10, 23. doi:10.1186/1743-8977-10-23

Martinez, A., Francisco-Marquez, M., Galano, A., 2010. Effect of Different Functional Groups on the Free Radical Scavenging Capability of Single-Walled Carbon Nanotubes. J. Phys. Chem. C 114, 14734-14739. doi:10.1021/jp1033382

Monteiro-Riviere, N.A., Inman, A.O., Zhang, L.W., 2009. Limitations and relative utility of screening assays to assess engineered nanoparticle toxicity in a human cell line. Toxicol. Appl. Pharmacol. 234, 222-235. doi:10.1016/j.taap.2008.09.030

Novoselov, K.S., Geim, A.K., Morozov, S.V., Jiang, D., Zhang, Y., Dubonos, S.V., Grigorieva, I.V., Firsov, A.A., 2004. Electric field effect in atomically thin carbon films. Science 306, 666-669. doi:10.1126/science.1102896 
Oberdörster, G., Ferin, J., Gelein, R., Soderholm, S.C., Finkelstein, J., 1992. Role of the alveolar macrophage in lung injury: studies with ultrafine particles. Environ. Health Perspect. 97, 193-199.

Pailleux, M., Boudard, D., Pourchez, J., Forest, V., Grosseau, P., Cottier, M., 2013. New insight into artifactual phenomena during in vitro toxicity assessment of engineered nanoparticles: Study of TNF- $\alpha$ adsorption on alumina oxide nanoparticle. Toxicol. In Vitro 27, 1049-1056. doi:10.1016/j.tiv.2013.01.022

Perkins, T.N., Shukla, A., Peeters, P.M., Steinbacher, J.L., Landry, C.C., Lathrop, S.A., Steele, C., Reynaert, N.L., Wouters, E.F., Mossman, B.T., 2012. Differences in gene expression and cytokine production by crystalline vs. amorphous silica in human lung epithelial cells. Part. Fibre Toxicol. 9, 6. doi:10.1186/1743-8977-9-6

Pulskamp, K., Diabaté, S., Krug, H.F., 2007. Carbon nanotubes show no sign of acute toxicity but induce intracellular reactive oxygen species in dependence on contaminants. Toxicol. Lett. 168, 58-74. doi:10.1016/j.toxlet.2006.11.001

Rakotomalala, R., 2005. TANAGRA : un logiciel gratuit pour l'enseignement et la recherche, in: RNTI-E-3. Presented at the EGC'2005, pp. 697-702.

Ruipérez, F., Mujika, J.I., Ugalde, J.M., Exley, C., Lopez, X., 2012. Pro-oxidant activity of aluminum: Promoting the Fenton reaction by reducing $\mathrm{Fe}(\mathrm{III})$ to $\mathrm{Fe}(\mathrm{II})$. J. Inorg. Biochem., Special Issue from the Eleventh International Symposium on Applied Bioinorganic Chemistry 117, 118-123. doi:10.1016/j.jinorgbio.2012.09.008

Sandberg, W.J., Låg, M., Holme, J.A., Friede, B., Gualtieri, M., Kruszewski, M., Schwarze, P.E., Skuland, T., Refsnes, M., 2012. Comparison of non-crystalline silica nanoparticles in IL-1 $\beta$ release from macrophages. Part. Fibre Toxicol. 9, 32. doi:10.1186/1743-8977-9-32 
Sasidharan, A., Panchakarla, L.S., Chandran, P., Menon, D., Nair, S., Rao, C.N.R., Koyakutty, M., 2011. Differential nano-bio interactions and toxicity effects of pristine versus functionalized graphene. Nanoscale 3, 2461-2464. doi:10.1039/C1NR10172B

Sasidharan, A., Panchakarla, L.S., Sadanandan, A.R., Ashokan, A., Chandran, P., Girish, C.M., Menon, D., Nair, S.V., Rao, C.N.R., Koyakutty, M., 2012. Hemocompatibility and Macrophage Response of Pristine and Functionalized Graphene. Small 8, 12511263. doi:10.1002/smll.201102393

Schinwald, A., Murphy, F.A., Jones, A., MacNee, W., Donaldson, K., 2011. Graphene-Based Nanoplatelets: A New Risk to the Respiratory System as a Consequence of Their Unusual Aerodynamic Properties. ACS Nano 6, 736-746. doi:10.1021/nn204229f

Tong, H., McGee, J.K., Saxena, R.K., Kodavanti, U.P., Devlin, R.B., Gilmour, M.I., 2009. Influence of acid functionalization on the cardiopulmonary toxicity of carbon nanotubes and carbon black particles in mice. Toxicol. Appl. Pharmacol. 239, 224232. doi:10.1016/j.taap.2009.05.019

Tran, C., Tantra, R., Donaldson, K., Stone, V., Hankin, S., Ross, B., Aitken, R., Jones, A., 2011. A hypothetical model for predicting the toxicity of high aspect ratio nanoparticles (HARN). J. Nanoparticle Res. 13, 6683-6698. doi:10.1007/s11051-0110575-9

Vietti, G., Ibouraadaten, S., Palmai-Pallag, M., Yakoub, Y., Bailly, C., Fenoglio, I., Marbaix, E., Lison, D., van den Brule, S., 2013. Towards predicting the lung fibrogenic activity of nanomaterials: experimental validation of an in vitro fibroblast proliferation assay. Part. Fibre Toxicol. 10, 52-52.

Wang, S., Tristan, F., Minami, D., Fujimori, T., Cruz-Silva, R., Terrones, M., Takeuchi, K., Teshima, K., Rodríguez-Reinoso, F., Endo, M., Kaneko, K., 2014. Activation routes 
for high surface area graphene monoliths from graphene oxide colloids. Carbon 76, 220-231. doi:10.1016/j.carbon.2014.04.071

Wang, X., Guo, J., Chen, T., Nie, H., Wang, H., Zang, J., Cui, X., Jia, G., 2012. Multi-walled carbon nanotubes induce apoptosis via mitochondrial pathway and scavenger receptor. Toxicol. Vitro Int. J. Publ. Assoc. BIBRA 26.

Wang, X., Xia, T., Ntim, S.A., Ji, Z., George, S., Meng, H., Zhang, H., Castranova, V., Mitra, S., Nel, A.E., 2010. Quantitative Techniques for Assessing and Controlling the Dispersion and Biological Effects of Multiwalled Carbon Nanotubes in Mammalian Tissue Culture Cells. Acs Nano 4, 7241-7252. doi:10.1021/nn102112b

Wörle-Knirsch, J.M., Pulskamp, K., Krug, H.F., 2006. Oops They Did It Again! Carbon Nanotubes Hoax Scientists in Viability Assays. Nano Lett. 6, 1261-1268. doi:10.1021/n1060177c

Yuan, J., Gao, H., Ching, C.B., 2011. Comparative protein profile of human hepatoma HepG2 cells treated with graphene and single-walled carbon nanotubes: An iTRAQ-coupled 2D LC-MS/MS proteome analysis. Toxicol. Lett. 207, 213-221. doi:10.1016/j.toxlet.2011.09.014

Zhang, T., Tang, M., Kong, L., Li, H., Zhang, T., Zhang, S., Xue, Y., Pu, Y., 2012. Comparison of cytotoxic and inflammatory responses of pristine and functionalized multi-walled carbon nanotubes in RAW 264.7 mouse macrophages. J. Hazard. Mater. 219-220, 203-212. doi:10.1016/j.jhazmat.2012.03.079

Zhang, Y., Ali, S.F., Dervishi, E., Xu, Y., Li, Z., Casciano, D., Biris, A.S., 2010. Cytotoxicity Effects of Graphene and Single-Wall Carbon Nanotubes in Neural Phaeochromocytoma-Derived PC12 Cells. ACS Nano 4, 3181-3186. doi:10.1021/nn1007176 


\section{SUPPLEMENTARY MATERIAL}

\section{A1. Acid functionalization}

Table A1Erreur ! Source du renvoi introuvable. sums up the optimized parameters for the acid functionalization of carbon nanomaterials.

Table A1: Acid functionalization protocol

\begin{tabular}{|l|l|l|l|l|}
\hline Nanomaterial name & Nanomaterial $(\mathbf{m g})$ & $\mathbf{H N O}_{\mathbf{3}}(\mathbf{m L})$ & $\mathbf{H}_{\mathbf{2}} \mathbf{S O}_{\mathbf{4}}(\mathbf{m L})$ & Duration (h) \\
\hline CNT & 100 & 75 & 25 & 6 \\
\hline CB & 160 & 120 & 40 & 9 \\
\hline NG & 50 & 120 & 40 & 9 \\
\hline
\end{tabular}

\section{A2. Stability of the nanomaterial suspensions}

The suspension stability was confirmed by dynamic light scattering. This technique gives the average diameter of a spherical particle of a density of 1 and with the same hydrodynamic volume ( $\mathrm{Z}$ average). So for non-spherical nanomaterials such as CNT and nano-graphite, it cannot be directly linked with a geometrical diameter. However, the evolution of the parameter can indicate if aggregation is occurring in the suspension. Figure A1 shows the evolution of $\mathrm{z}$ average along the time. As it did not change for $96 \mathrm{~h}$, the conclusion was made that the suspensions were stable long enough to carry out the toxicological tests.

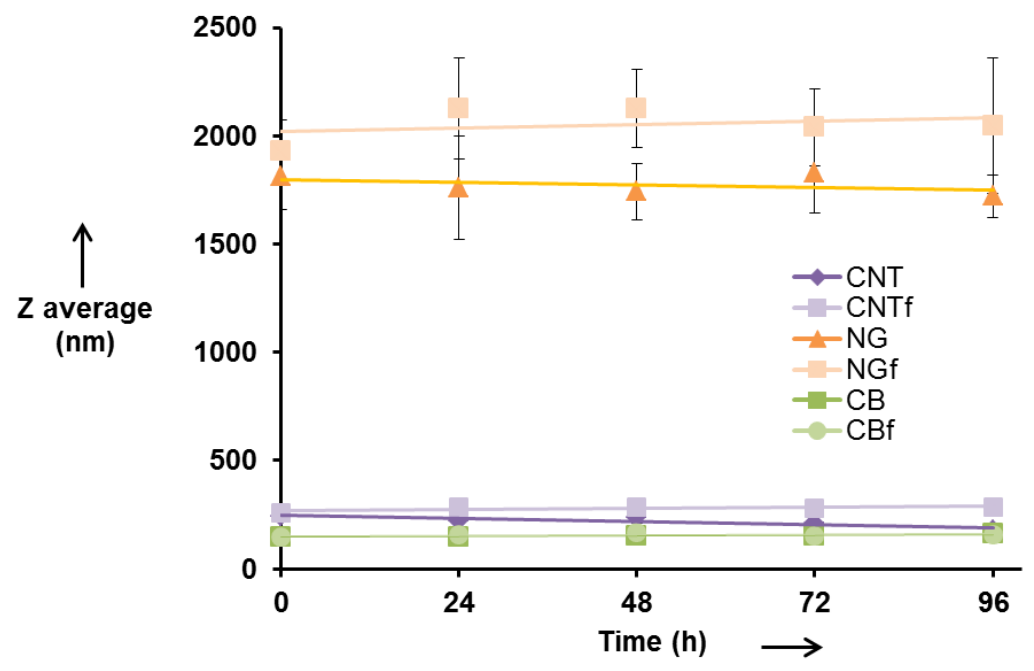

Figure A1 : Stability of the nanomaterials over $96 \mathrm{~h}$ in supplemented medium. Initial suspensions were dispersed by $5 \mathrm{~min}$ sonication (30\%, $3 \mathrm{~mm}$ probe). 


\section{A3. ROS assay, biases correction}

Our previous study (Figarol et al. 2014) has shown that the ROS assay can be biased by MWCNT. A supplementary assay was thus carried out to assess and correct these biases for all carbon nanomaterials. The fluorescence of the DCF probe $\left(2^{\prime}, 7^{\prime}\right.$ dichlorodihydrofluorescein) at $0,10,100,1000 \mathrm{nM}$ was measured in acellular complemented culture medium. Carbon nanomaterials were added at concentrations of 15, 30, 60, and 120 $\mu \mathrm{g} . \mathrm{mL}^{-1}$. The difference between the fluorescence with and without carbon nanomaterials was calculated for each sample. Figure A2 shows an example of the obtained correction curves, and Table A2 summarizes the correction for each MWCNT sample. This correction was the applied to the data from the ROS (reactive oxygen species) assay to obtain corrected values.

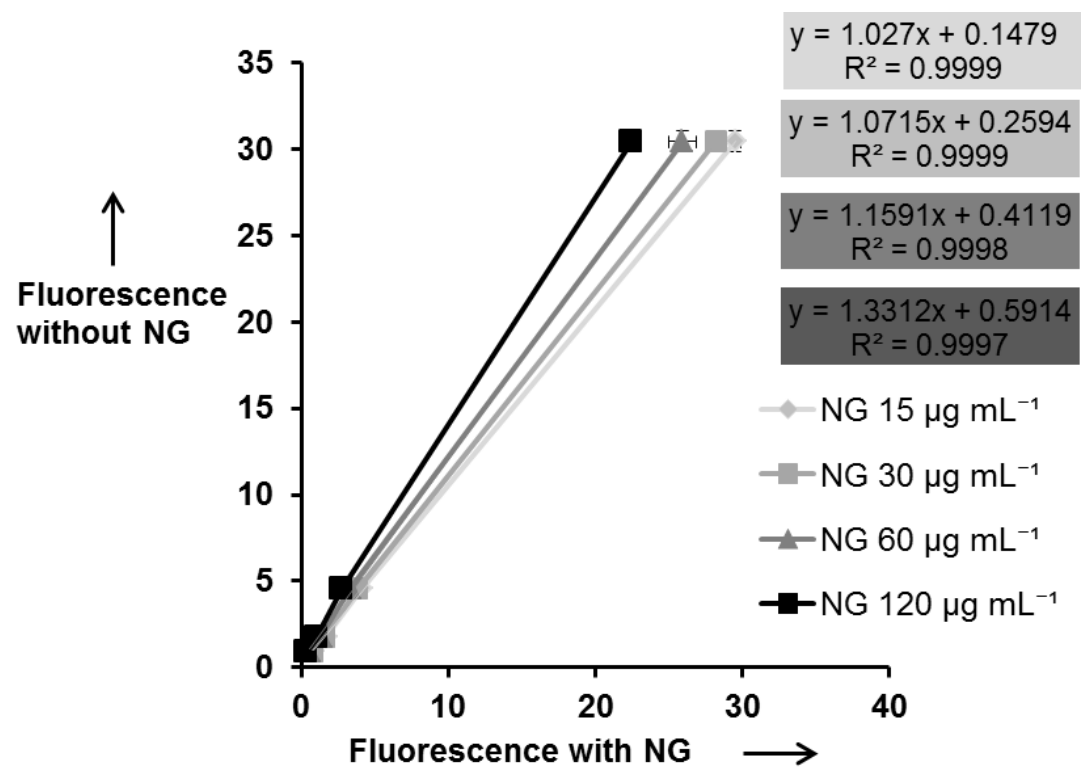

Figure A2: Bias between fluorescence of 0 to $10000 \mathrm{nM}$ DCF, with and without pristine nano-graphite.

Table A2: Corrections of bias in the oxidative stress detection assay ( $\left.\mathrm{R}^{2}>0.98\right)$.

\begin{tabular}{|c|c|c|c|c|}
\hline Powder & $\begin{array}{l}\text { Correction at } 15 \\
\mu \text { g.mL }\end{array}$ & $\begin{array}{l}\text { Correction at } 30 \\
\mu \text { g.mL } \mathrm{mL}^{-1}\end{array}$ & $\begin{array}{l}\text { Correction at } 60 \\
\mu \mathrm{g} . \mathrm{mL}^{-1}\end{array}$ & $\begin{array}{l}\text { Correction at } 120 \\
\mu \mathrm{g} \cdot \mathrm{mL}^{-1}\end{array}$ \\
\hline $\mathrm{CNT} \mathrm{n}^{\circ} 1$ & $y=1.37 x+0.46$ & $y=1.69 x+0.63$ & $y=2.59 x+0.79$ & $y=4.53 x+0.93$ \\
\hline $\mathrm{CNT} \mathrm{n}^{\circ} 2$ & $y=1.42 x+0.26$ & $y=1.83 x+0.45$ & $y=2.67 x+0.67$ & $y=4.52 x+0.86$ \\
\hline $\mathrm{CNT} n^{\circ} 3$ & $y=1.38 x+0.42$ & $y=1.91 x+0.57$ & $y=2.87 x+0.78$ & $y=5.10 x+0.94$ \\
\hline
\end{tabular}




\begin{tabular}{|c|c|c|c|c|}
\hline $\operatorname{CNTf}^{\circ} 1$ & $y=1.23 x+0.37$ & $y=1.49 x+0.45$ & $y=2.09 x+0.59$ & $y=3.11 x+0.69$ \\
\hline CNTf n ${ }^{\circ} 2$ & $y=1.22 x+0.22$ & $y=1.40 x+0.41$ & $y=1.82 x+0.60$ & $y=2.72 x+0.70$ \\
\hline CNTf n ${ }^{\circ} 3$ & $y=1.15 x+0.13$ & $y=1.30 x+0.25$ & $y=1.60 x+0.43$ & $y=2.23 x+0.60$ \\
\hline$\overline{\mathrm{CB} \mathrm{n}^{\circ} 1}$ & $y=1.25 x-0.17$ & $y=1.46 x-0.03$ & $y=1.78 x+0.93$ & $y=2.56 x+1.14$ \\
\hline $\mathrm{CB} \mathrm{n}^{\circ} 2$ & $y=1.21 x+0.26$ & $y=1.47 x+0.40$ & $y=1.84 x+0.68$ & $y=2.87 x+0.79$ \\
\hline $\mathrm{CB} \mathrm{n}^{\circ} 3$ & $y=1.19 x+0.25$ & $y=1.28 x+0.47$ & $y=1.65 x+0.48$ & $y=2.40 x+0.60$ \\
\hline $\mathrm{CBf} \mathrm{n}^{\circ} 1$ & $y=1.18 x+0.44$ & $y=1.34 x+0.43$ & $y=1.58 x+0.79$ & $y=2.10 x+1.07$ \\
\hline $\operatorname{CBf} n^{\circ} 2$ & $y=1.20 x+0.10$ & $y=1.32 x+0.42$ & $y=1.60 x+0.58$ & $y=2.32 x+0.74$ \\
\hline $\mathrm{CBf} \mathrm{n}^{\circ} 3$ & $y=1.10 x+0.18$ & $y=1.14 x+0.42$ & $y=1.35 x+0.48$ & $y=1.81 x+0.61$ \\
\hline $\mathrm{NG} \mathrm{n}^{\circ} 1$ & $y=1.03 x+0.16$ & $y=1.07 x+0.27$ & $y=1.16 x+0.43$ & $y=1.33 x+0.61$ \\
\hline $\mathrm{NG} \mathrm{n}^{\circ} 2$ & $y=1.08 x+0.05$ & $y=1.18 x+0.24$ & $y=1.26 x+0.47$ & $y=1.56 x+0.64$ \\
\hline $\mathrm{NG} \mathrm{n}{ }^{\circ} 3$ & $y=1.06 x+0.20$ & $y=1.13 x+0.32$ & $y=1.30 x+0.47$ & $y=1.65 x+0.69$ \\
\hline NGf $n^{\circ} 1$ & $y=0.98 x+0.26$ & $y=1.12 x+0.14$ & $y=1.16 x+0.32$ & $y=1.27+0.56$ \\
\hline NGf $n^{\circ} 2$ & $y=1.02 x+0.14$ & $y=1.12 x+0.17$ & $y=1.21 x+0.37$ & $y=1.48 x+0.55$ \\
\hline NGf $n^{\circ} 3$ & $y=1.00 x+0.33$ & $y=1.03 x+0.44$ & $y=1.19 x+0.45$ & $y=1.33 x+0.64$ \\
\hline
\end{tabular}

\section{A3. Raman spectra}

For crystallized carbon nanomaterials, Raman spectra exhibited two main bands (Figure A3). They are called the D-band $\left(1340 \mathrm{~cm}^{-1}\right)$ and the G-band $\left(1570 \mathrm{~cm}^{-1}\right)$. Two overtone peaks were also observed $\left(>2500 \mathrm{~cm}^{-1}\right)$. 

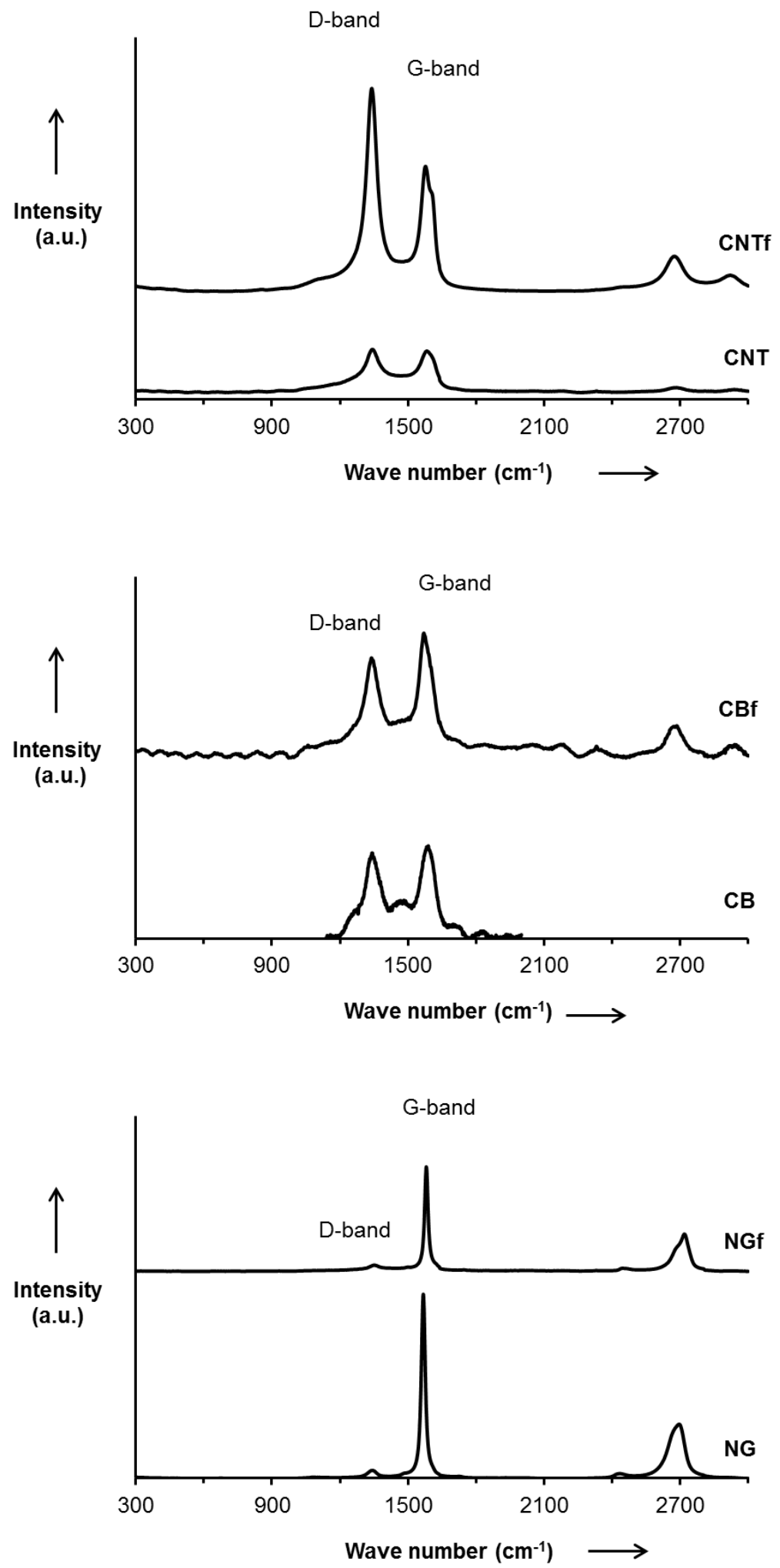

Figure A3: Raman spectra of pristine and functionalized carbon nanotubes (CNT and CNTf), carbon black (CB and $\mathrm{CBf}$ ), and nano-graphite (NG and NGf). a.u.: arbitrary units. The $\mathrm{CB}$ spectrum is limited from 1000 to $2000 \mathrm{~cm}^{-1}$ because it was difficult to obtain a workable spectrum otherwise. 
A4. Comparison of the effects between pristine and functionalized nanomaterials in terms of surface area

A)

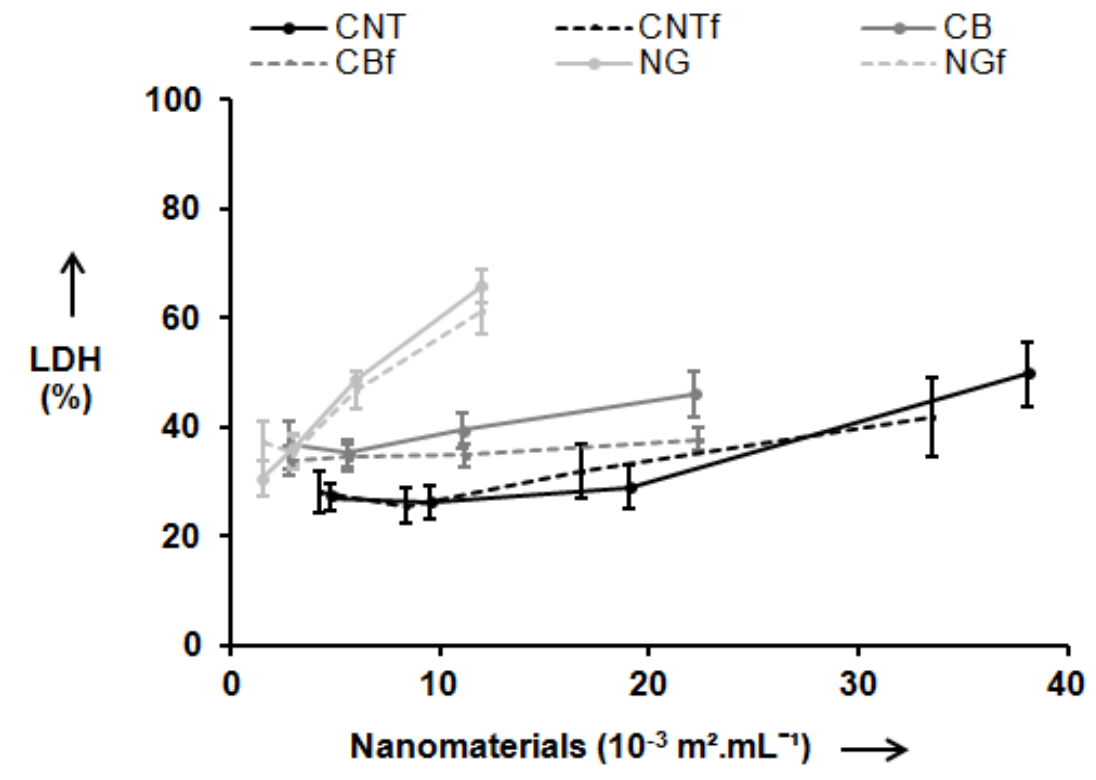

B)

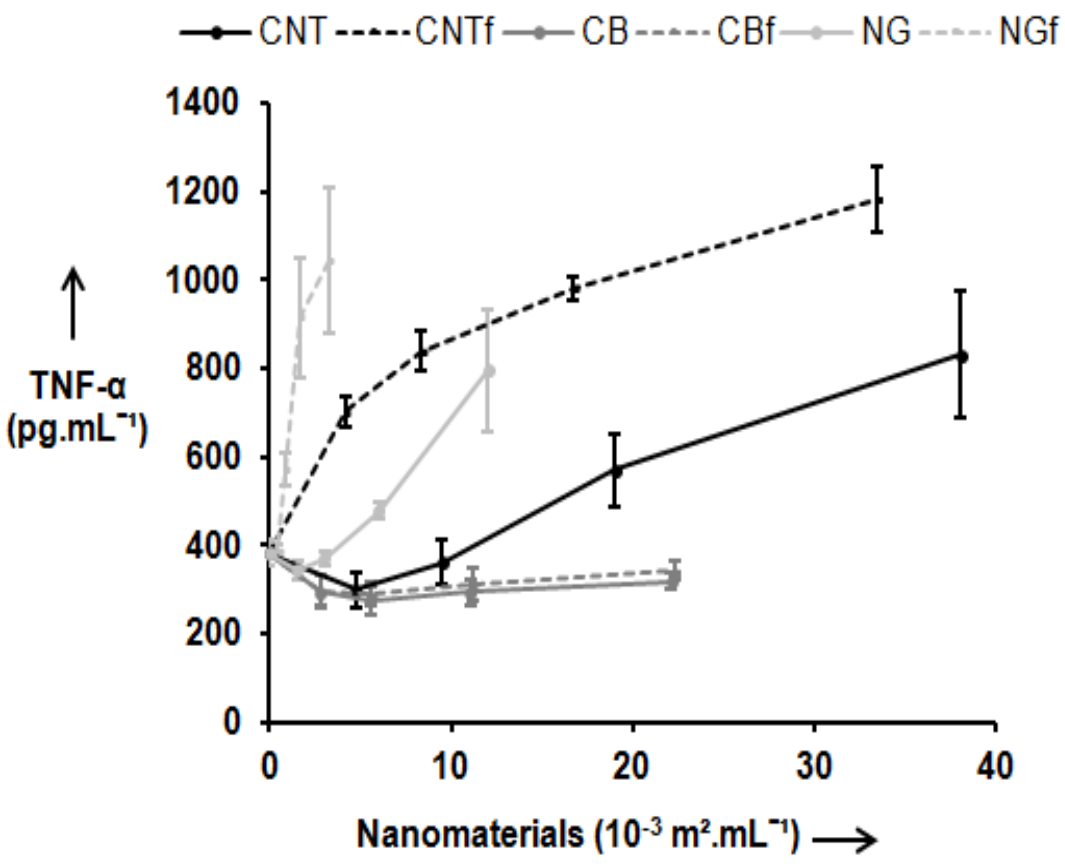


C)

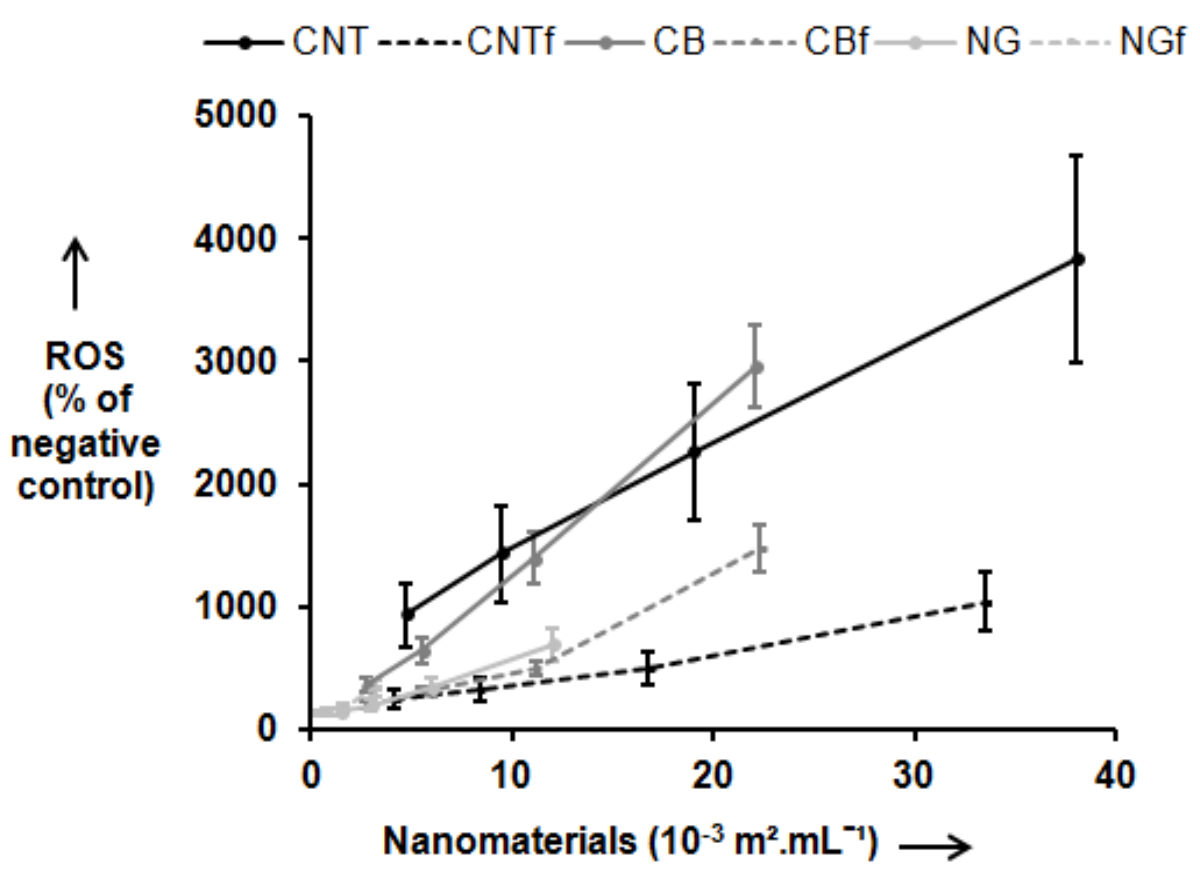

Figure A4: Impact of the functionalization on the cytotoxicity (A), the pro-inflammatory response (B) and the oxidative stress (C) triggered by carbon-based nanomaterials. Doses were expressed in surface. The cytotoxicity was determined by LDH release after a $24 \mathrm{~h}$ exposure. Results are reported to the total cellular LDH measured after lysis of control cells. The pro-inflammatory activity was evaluated by the level of TNF- $\alpha$ after a $24 \mathrm{~h}$ exposure. Oxidative stress was determined by ROS production after a 90 min exposure. Results are expressed as a percentage of the negative control.

\section{A5. Cell morphology}

Similar trends were found when comparing the cell morphology after an exposure to pristine or functionalized carbon nanomaterials (Figure 5). Interaction between carbon nanomaterials and cells were visible and seemed stronger with CB than CNT or NG. 


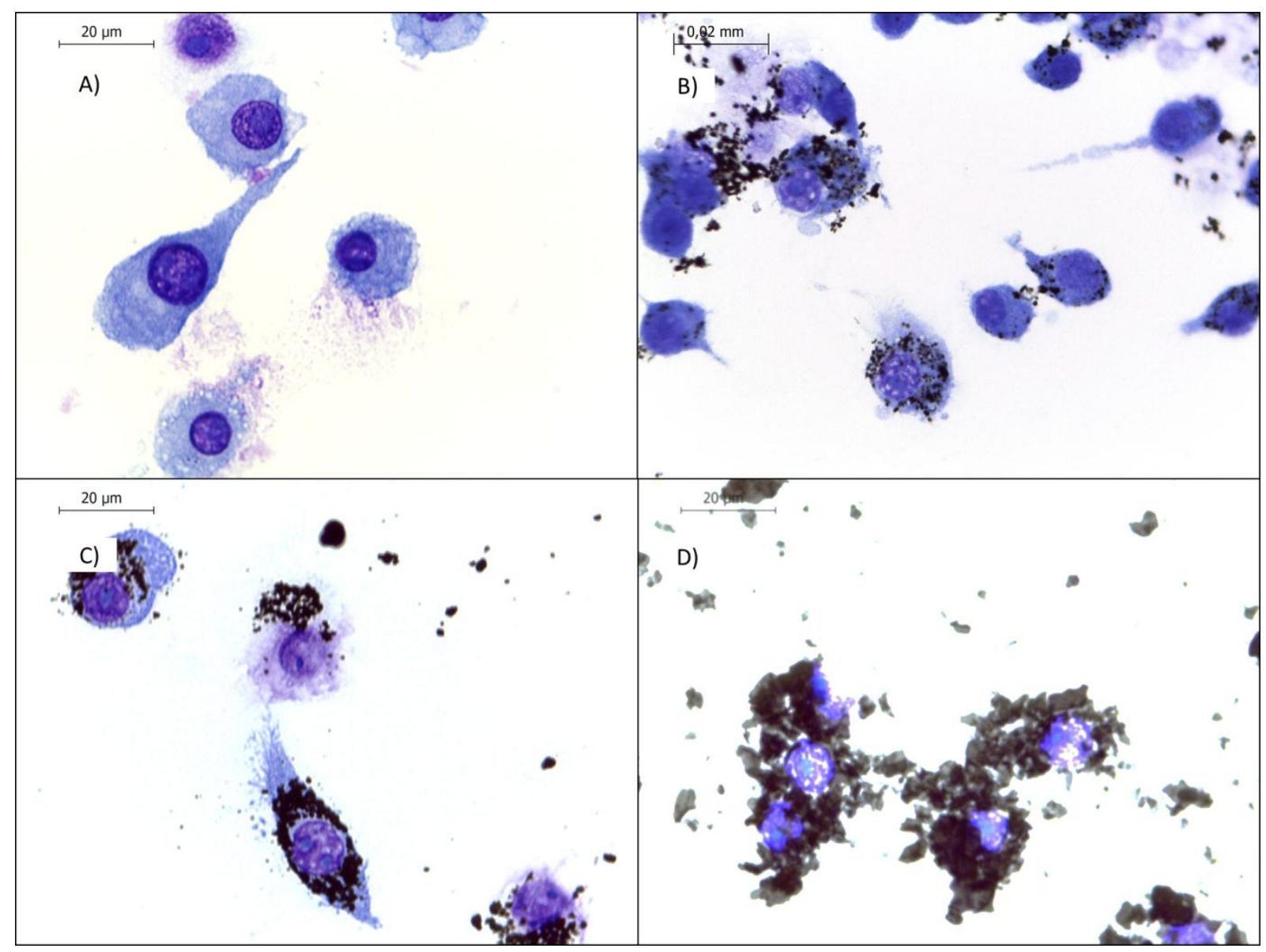

Figure A5: Microscopic images of RAW 264.7 cells exposed for $24 \mathrm{~h}$ to $15 \mu \mathrm{g} \cdot \mathrm{mL}^{-1}$ of carbon nanomaterials after a May-Grünwald-Giemsa staining. A) negative control, cells alone, B) pristine carbon nanotubes $(\mathrm{CNT}), \mathrm{C})$ pristine carbon black (CB), and D) pristine nanographite (NG).

\section{REFERENCE}

Figarol A, Pourchez J, Boudard D, et al (2014) Biological response to purification and acid functionalization of carbon nanotubes. J Nanoparticle Res 16:1-12. doi: 10.1007/s11051-014-2507-y 